Check for updates

Cite this: J. Mater. Chem. A, 2018, 6 , 11564

Received 29th March 2018 Accepted 22nd May 2018

DOI: $10.1039 / c 8 t a 02919 a$

rsc.li/materials-a

\section{Realising the environmental benefits of metal- organic frameworks: recent advances in microwave synthesis}

\author{
leuan Thomas-Hillman, (D) $\dagger$ Andrea Laybourn, $\mathbb{D} \dagger^{\star}$ Chris Dodds (ID \\ and Samuel W. Kingman (D)
}

Metal-organic frameworks (MOFs) are a broad class of porous crystalline materials that show great potential for a wide-range of applications in areas such as energy and environmental sustainability. MOFs can show significant advantages in gas selectivity and separation over traditional adsorbents such as zeolites and activated carbons since they are tuneable both in terms of porosity and chemical functionality. The ability to control the pore environment of the MOF is one of their remarkable advantages and affords control over the structure and properties required for specific applications. Despite these advantages, the industrial adoption of MOFs is slow owing to the paucity of scalable, environmentally sustainable manufacturing methods and higher costs compared to zeolites. Microwave (MW) technology is an extremely promising method of MOF production owing to significantly reduced reaction times and subsequently lower process energy consumption, control over MOF properties, and the ability to produce MOFs and MOF-hybrids otherwise difficult to isolate or unobtainable through other synthetic routes. However, the ability to produce the multiple kilogram or even tonne quantities of MOFs required by industry using MW technology is yet to be achieved owing to little or no understanding of the interaction(s) of reactants and MOFs with the electric field, and crucially, how this informs the design of the scale up processes. This review aims to bridge this gap in knowledge by (1) highlighting recent advances in understanding of MW-MOF interactions and areas for future focus; (2) providing an up-to-date and comprehensive summary of literature on MW synthesis of MOFs, focusing on examples where MW heating has facilitated novel and unique results in the laboratory; and (3) emphasising the advantages, challenges and current steps and methodologies required towards industrial-scale MW production of MOFs.
Faculty of Engineering, University of Nottingham, Nottingham, NG7 2RD, UK. E-mail: Andrea.Laybourn@nottingham.ac.uk $\dagger$ These authors contributed equally to this work.

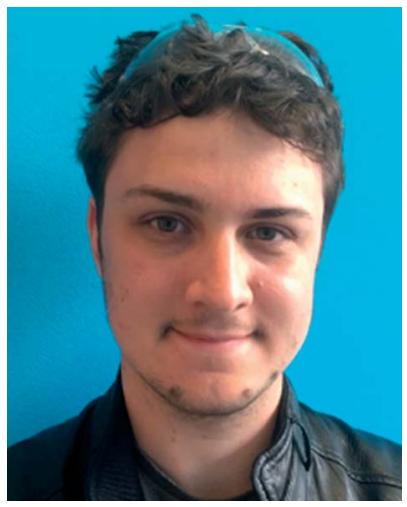

Ieuan Thomas-Hillman received his Masters of Chemistry degree from Cardiff University in 2016. $\mathrm{He}$ is currently undertaking a PhD at the University of Nottingham on the synthesis of metal-organic frameworks using microwave technology.

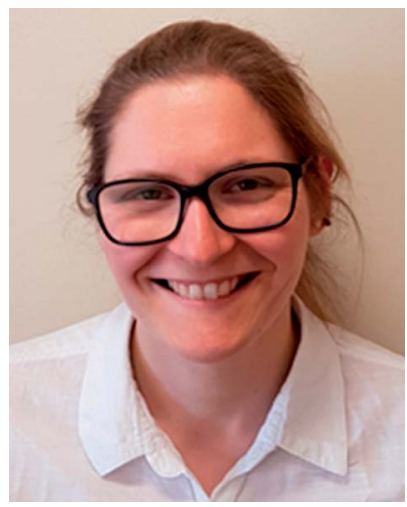

Andrea Laybourn received her Masters of Chemistry and PhD from the University of Liverpool in 2008 and 2012, respectively. She currently holds a highly prestigious Nottingham Research Fellowship in the Faculty of Engineering at the University of Nottingham. Her research expertise is in the synthesis and characterisation of porous materials underpinned by her background in materials chemistry with a particular focus on the use of microwave heating for ultra-fast materials synthesis. 


\section{Introduction}

Metal-organic frameworks (MOFs) ${ }^{2}$ are a specific subset of coordination polymers, comprised of metal nodes/clusters and organic linkers, which combine together forming porous supramolecular networks analogous to zeolites in structure. The field of MOFs first emerged in the 1990s with preliminary work performed by Hoskins and Robson., ${ }^{3,4}$ In 1995 Yaghi et $a l .{ }^{5-7}$ used the term "metal-organic framework" for the first time, showing selective accommodation of guest species in the porous material. Since these early reports, an exponentially increasing number of frameworks have been synthesised and studied, leading to the development of one of the hottest areas of chemical research with over 17000 papers in the field published to date, as shown in Fig. $1 .^{8}$

MOFs have attracted extensive and continually increasing interest from both academia and, more recently, industry owing to their unprecedented porosity and structural and functional diversity. Proposed applications of MOFs include separations, ${ }^{9-11}$ gas storage, ${ }^{11}$ catalysis, ${ }^{11,12}$ sensing, ${ }^{11,13-15}$ as synthetic precursors to porous materials ${ }^{16,17}$ and as stimuli-responsive materials. ${ }^{18,19}$ A significant advantage of MOFs over traditional adsorbents such as zeolites and activated carbons is the ability to tailor the pore environment of the MOF which affords control over the structure and properties required for any specific application. $^{20}$

Typically MOFs are prepared by solvothermal batch reactions whereby solutions of metal salt and organic linker are heated above the boiling point of the solvent and retained under autogenous pressure for up to one week. ${ }^{21}$ This synthetic route has inherent problems as it can produce MOFs of low quality (reduced crystallinity and porosity and non-uniform particle size and morphology, all of which are vital for processing to tailor practical applications). Additional problems include poor reproducibility between batches, long reaction times, large volumes of toxic solvent, and high cost of scale-up along with significant energy consumption. ${ }^{22}$ The development of

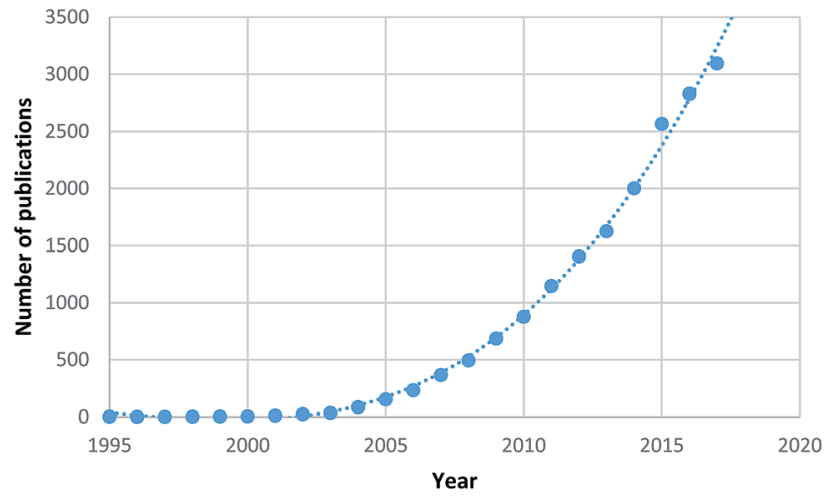

Fig. 1 Number of MOF papers published by year highlighting the high level of research interest. ${ }^{8}$

technologies that reproducibly give high-quality MOFs whilst reducing the cost of manufacture in an efficient and sustainable way is a key enabling step in the transfer of MOF research from the laboratory to industry and the ultimate realisation of the environmental process benefits that MOFs offer.

Over the past two decades microwave technology has been investigated as an alternative heating method in the preparation of MOFs with a rapidly growing number of publications in this field (over 200 papers published to date). ${ }^{23}$ Microwave heating is a tremendously exciting route for MOF production as it offers the following benefits; considerably reduced synthesis times (from hours to seconds) and therefore significantly reduced energy consumptions ${ }^{\mathbf{2 4 , 2 5}}$ and control over MOF properties (particle size, ${ }^{24,26,27}$ morphology ${ }^{25}$ and phase-selectivity ${ }^{28}$ ). Importantly, through rapid and selective heating, microwave technology has been used to prepare MOFs and MOF-hybrids otherwise difficult to isolate or unobtainable through other synthetic routes. Despite this hugely exciting research, the majority of published approaches have involved generic lab microwave systems and experiments that essentially use microwaves as a mechanism for simply rapid heating of solvent.

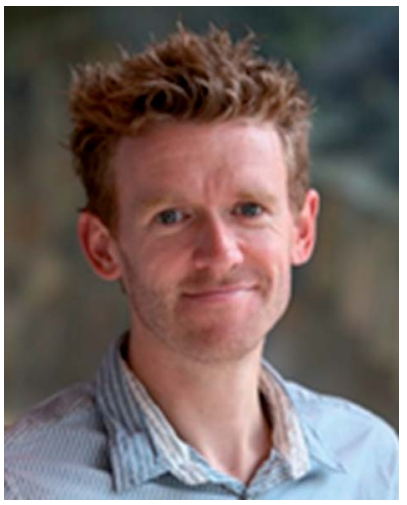

Chris Dodds is an Associate Professor at the University of Nottingham. He has fifteen years' experience in the design, scale-up and evaluation of industrial microwave processes and an in depth understanding of the interaction of microwave energy with a wide range of materials. He is an inventor on over 25 patents and an author of over 30 journal papers. Together with Prof. Kingman at the University of Nottingham, he has developed extensive experimental facilities for microwave processing research with many hundreds of $k W$ of microwave power available coupled with unique metrology and applicator systems.

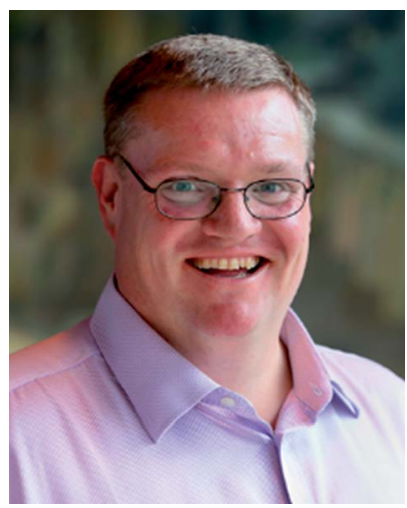

Sam Kingman is the Associate Faculty Pro-Vice-Chancellor and Deputy Head of the Faculty of Engineering at the University of Nottingham. He was awarded a personal chair at Nottingham in 2006. In 2011 he was the recipient of the Bielby Medal and Prize award by the Society of Chemical Industry, the Royal Society of Chemistry and the Institute of Materials, Minerals and Mining. Professor Kingman has published over 150 journal papers, holds over 180 patents in the field of industrial microwave processing and has lead the development and construction of the world's largest industrial microwave heating processes. 
The same is also true of attempts to process zeolites using microwave heating where a number of laboratory-scale studies have been reported using domestic microwave ovens. ${ }^{29}$ In order to facilitate future developments in microwave synthesis of MOFs (and zeolites) beyond the laboratory, greater understanding of the microwave parameters that are essential for scale-up is required. To this end, we present an up-to-date critical survey of literature relevant to MW synthesis of MOFs. This paper is organised as follows: first the theory of microwave heating and parameters that inform the design of scaled-up MW processes are discussed. Next we provide a comprehensive summary of MOF synthesis using microwave heating and compare materials prepared by this method to those obtained by conventionally heated solvothermal routes. Here we focus on reports of novel results exclusive to microwave heating as it is well-known that for economic impact MWs must be able to achieve outcomes that no other thermal processing method can due to high capital expenditure. ${ }^{1}$ Finally we discuss the challenges and current progress towards industrial-scale MW production of MOFs. This review aims to assist the progression of microwave-assisted MOF synthesis research by systematically organising previous knowledge in this area across the reported literature in an accessible and informative manner and by identifying areas for future growth.

\section{The theory of microwave heating and its application to MOF synthesis}

In conventional heating energy is delivered to the material (or reaction mixture in the case of MOF synthesis) by conductive, convective or radiative heat transfer. In dielectric or microwave heating, energy is delivered through interaction of the electronic structure of the material with the alternating electric field. The extent to which the material interacts with the electric field can be characterised by the dielectric properties of the mixture (specifically the dielectric constant, $\varepsilon^{\prime}$, and dielectric loss, $\left.\varepsilon^{\prime \prime}\right){ }^{30,31} \varepsilon^{\prime}$ indicates the ability of the material to store energy through a form of polarisation, while $\varepsilon^{\prime \prime}$ is the ability of the material to convert the stored energy to heat. ${ }^{30,31}$ At microwave frequencies, two polarisation or loss mechanisms occur, namely dipolar and ionic polarisation. ${ }^{30,32,33}$ Dipolar mechanisms occur for molecules that have a permanent dipole, such as water and $N, N$-dimethylformamide. These molecules experience torque which forces them to reorient in the direction of the applied electric field. ${ }^{32,33}$ Ionic mechanisms occur in solutions containing ions, such as dissolved salts; in this case the cations and anions are displaced by the oscillating electric field. ${ }^{30,32,33}$ In both dipolar and ionic polarisation, the species in solution experience frictional forces from neighbouring molecules which is lost as heat..$^{30,32,33}$ It is important to note that the dielectric properties ( $\varepsilon^{\prime}$ and $\left.\varepsilon^{\prime \prime}\right)$ greatly depend on a number of factors including, but not limited to, frequency of the electromagnetic field, temperature, physical state (solid, liquid, or gas), composition and concentration. ${ }^{30,32,33}$ Therefore, $\varepsilon^{\prime}$ and $\varepsilon^{\prime \prime}$ may vary considerably during a microwave heating process and determination of their values for each reaction is required for detailed understand of the interaction of the electric field with the material(s) of interest. ${ }^{31}$

The dielectric properties of individual components within the bulk reaction mixture indicate which reactants interact more strongly with the electric field and thus heat more effectively. Generally, reactants with high values of $\varepsilon^{\prime \prime}$ heat well and those with low $\varepsilon^{\prime \prime}$ heat poorly. If there are large differences in the dielectric properties, then individual components will be selectively heated and become much hotter than the bulk. ${ }^{34}$ Through dielectric properties measurements, Laybourn et al. ${ }^{34}$ showed that aqueous metal(III) salts interact strongly with the electric field $\left(\varepsilon^{\prime \prime}>35\right)$, whereas terephthalic acid exhibits little interaction $\left(\varepsilon^{\prime \prime}<0.03\right)$. These results showed that the aqueous metal(III) salts will absorb more power and, therefore, heat more effectively than the ligand. This was the first indication of a selective heating process in MOF synthesis by microwaves. Further evidence of a selective heating mechanism in microwave synthesis of MOFs was also provided, for the first time, by Laybourn et $a{ }^{25}$ Using a specifically designed single mode microwave applicator capable of housing a pressure vessel in a well-defined electric field. The authors showed an increase in yield of MIL-53(Al) (MIL = Materials Institute Lavoisier) with increasing average absorbed power at a constant total absorbed energy. Importantly, the reports by Laybourn et al. showed that while still often conducted in pressurised vessels and with identical reaction mixtures, microwave synthesis of MOFs proceeds via a different heating mechanism to conventionally heated reactions. Selective heating can be advantageous as it may give reaction products unobtainable through conventional heating and can result in lower production of unwanted sideproducts; this is discussed further in Section 3. Crucially it also gives rise for the potential to significantly reduce energy consumption in a process as the whole bulk of the reaction mixture does not need to be heated to the same overall temperature as in a conventional process.

As well as governing the ability of the material/bulk reaction mixture to absorb and convert microwave energy to heat, the dielectric properties also directly affect the distribution of the electric field within the microwave cavity and the power density dissipation, as shown in eqn (1):

$$
P_{\mathrm{d}}=2 \pi f \varepsilon_{0} \varepsilon^{\prime \prime} E^{2}
$$

where $P_{\mathrm{d}}$ is the power density dissipation $\left(\mathrm{W} \mathrm{m}^{-3}\right), f$ is frequency $(\mathrm{Hz}), \varepsilon_{0}$ is the permittivity of free space $\left(8.854 \times 10^{12} \mathrm{~F} \mathrm{~m}^{-1}\right), E$ is the electric field strength in the material $\left(\mathrm{V} \mathrm{m}^{-1}\right)$.

In addition, the temperature rise resulting from absorption of microwave energy by the material is related to the power density dissipation, as shown in eqn (2):

$$
P_{\mathrm{d}}=c \rho \frac{\mathrm{d} T}{\mathrm{~d} t}
$$

where $c$ is the specific heat capacity $\left(\mathrm{J} \mathrm{kg}^{-1}{ }^{\circ} \mathrm{C}^{-1}\right), \rho$ is density of the material $\left(\mathrm{kg} \mathrm{m}^{-3}\right), \mathrm{d} T$ is the change in temperature $\left({ }^{\circ} \mathrm{C}\right)$ and $\mathrm{d} t$ is the time increment (s).

From eqn (1), it is evident that the power density dissipation varies proportionally to $\varepsilon^{\prime \prime}$ and frequency, and by a power of two 
with the electric field. Consequently, significant increases in electric field strength, frequency and $\varepsilon^{\prime \prime}$ will result in greatly increased power dissipation densities and thus heating rates (see eqn (2)). Therefore, it is essential to quantify the dielectric properties and electric field distribution when designing microwave cavities as this will control the power density in the heated phases of the material under treatment.

The final parameter crucial to the development of microwave heated systems is the penetration depth. The penetration depth is defined as the point at which the electric field reaches $37 \%$ of its original value; the amplitude of the electric field diminishes owing to absorption of the field by the material and conversion into heat. The penetration depth depends greatly on the dielectric properties of the material, as shown in eqn (3):

$$
D_{\mathrm{p}}=\frac{\lambda_{0}}{2 \pi \sqrt{2 \varepsilon^{\prime}}} \frac{1}{\sqrt{\left[\left\{1+\left(\frac{\varepsilon^{\prime \prime}}{\varepsilon^{\prime}}\right)^{2}\right\}^{0.5}-1\right]}}
$$

where $D_{\mathrm{p}}$ is the penetration depth $(\mathrm{m}), \lambda_{0}$ is the free space wavelength of the incident radiation $(\mathrm{m}), \varepsilon^{\prime}$ is the dielectric constant and $\varepsilon^{\prime \prime}$ is the dielectric loss.

The penetration depth is an important parameter in microwave cavity design as it gives an indication of heat distribution within the material, i.e. whether heating is taking place primarily on the surface of the reaction mixture/material or volumetrically (heating the bulk). To put this into perspective, a typical MIL$53(\mathrm{Al})$ reaction mixture containing $\mathrm{Al}_{2}\left(\mathrm{SO}_{4}\right)_{3} \cdot 18 \mathrm{H}_{2} \mathrm{O}(0.77 \mathrm{~g}, 1.2$ $\mathrm{mmol})$, terephthalic acid $(0.19 \mathrm{~g}, 1.2 \mathrm{mmol})$ and deionized water $(6.7 \mathrm{~mL})$ has a penetration depth of $0.38 \mathrm{~cm} .^{25}$

From this section, it should now be clear that the dielectric properties, power density, electric field distribution and penetration depth are all vital in microwave processing as these variables underpin the successful integration of microwave energy with chemical reactor systems capable of delivering the required materials, consistently at high quality and at the correct cost base and with minimal environmental impact. The literature presented in the following sections will be reviewed in this context.

\section{Microwave synthesis of MOFs: a comparison of time with conventionally heated reactions}

\subsection{Background}

With the prevalence of microwave heating in organic chemistry and the availability of 'off the shelf' microwave reactors, it is unsurprising that this technology has been increasingly applied to the synthesis of MOFs. Microwave technology has been used to prepare MOFs from transition metals ${ }^{35-41}$ p-block metals (namely lead and indium), ${ }^{\mathbf{4 2 - 4 4}}$ alkali and alkaline earth metals, ${ }^{45-50}$ lanthanides and actinides; ${ }^{51-56}$ bimetallic MOFs; ${ }^{57}$ and mixed-linker MOFs. ${ }^{58-61}$ Additionally, microwave heating has been used in the synthesis of MOF linkers, ${ }^{62-66}$ MOF thin films,${ }^{67-70}$ membranes, ${ }^{71-76}$ for surface deposition ${ }^{43,67,70,77-83}$ and for solvent-free synthesis of MOFs. ${ }^{\mathbf{8 4 , 8 5}}$ Early reports typically used microwave heating as a faster route to known MOFs by adapting the conventionally heated solvothermal reaction conditions. Only recently has microwave synthesis been used independently for discovery of new MOFs facilitated by the ability to screen many reaction conditions in a shorter period of time compared to conventional heating routes. ${ }^{51,86-90}$

The next sub-sections (3.2 to 3.6) of this paper summarise the effect of microwave heating on the reaction conditions and properties of MOFs produced. Where possible, information about microwave parameters such as power, treatment time, and type of cavity (or reactor) have been included and are discussed. However in all reported examples there is no information about the penetration depth and so it is not currently possible to determine whether the bulk synthesis mixture was heated by microwave energy or if the surface was heated by MW and the inside heated through conductive heat transfer. This is a major limitation in much of the literature currently published as it is impossible, without this knowledge, to determine if the systems were actually heated by microwave energy or a shell of the material heated by microwave energy with the majority of the reaction mixture being heated through conductive heat transfer from a microwave heated zone into the bulk.

\subsection{Influence of microwave heating on MOF reaction time}

The shorter reaction time enabled by microwave treatment has been noted across all synthetic chemistry and was readily apparent in the first report of microwave synthesis of a MOF in $2005 .{ }^{91}$ In this pioneering work Jhung et al. prepared MIL-100 via microwave and conventional routes by heating an aqueous mixture of metallic chromium, trimesic acid and hydrofluoric acid in a $1.0: 0.67: 2.0$ molar ratio to $220^{\circ} \mathrm{C}$ (the conditions for MIL-100 synthesis were previously established by Férey et $\left.a l .{ }^{92}\right) .{ }^{91}$ The significance of microwave heating was demonstrated by a marked reduction in synthesis time without affecting the yield; $44 \%$ after 4 hours reaction in a Mars-5 CEM multimode microwave reactor (power not given) compared to $45 \%$ after 4 days in a conventionally heated oven. ${ }^{91}$ Thermo-gravimetric and X-ray diffraction analyses showed the MIL-100 products to be consistent regardless of heating method, however, a slightly reduced pore volume (from 1.16 to $0.97 \mathrm{~cm}^{3} \mathrm{~g}^{-1}$ ) was exhibited by the microwave-synthesised material.

Since 2005, microwave heating has continually been shown to facilitate a progressive reduction in MOF reaction time (in some cases the time is reduced by up to $99.8 \%$, as presented in Table 1). Many papers show the ability to synthesise MOFs using microwave energy in the order of minutes. ${ }^{86}$ Two reports have also demonstrated the synthesis of MOFs in as little as 25 ( $1 \mathrm{~mL}$ solution heated in a model 520A microwave reactor from Resonance Instrument Inc.) ${ }^{24}$ and 4.3 seconds (6.7 mL solution heated in bespoke system with a cavity designed to enable precise control of the power and energy input to the reaction mixture); ${ }^{25,34}$ with the latter representing the fastest reported synthesis of a MOF on the tens of milligram scale to date. ${ }^{25,34}$

\subsection{Influence of microwave heating on MOF crystal size}

A consequence of the shorter reaction times afforded by microwave heating is the reduction in crystal and/or particle 


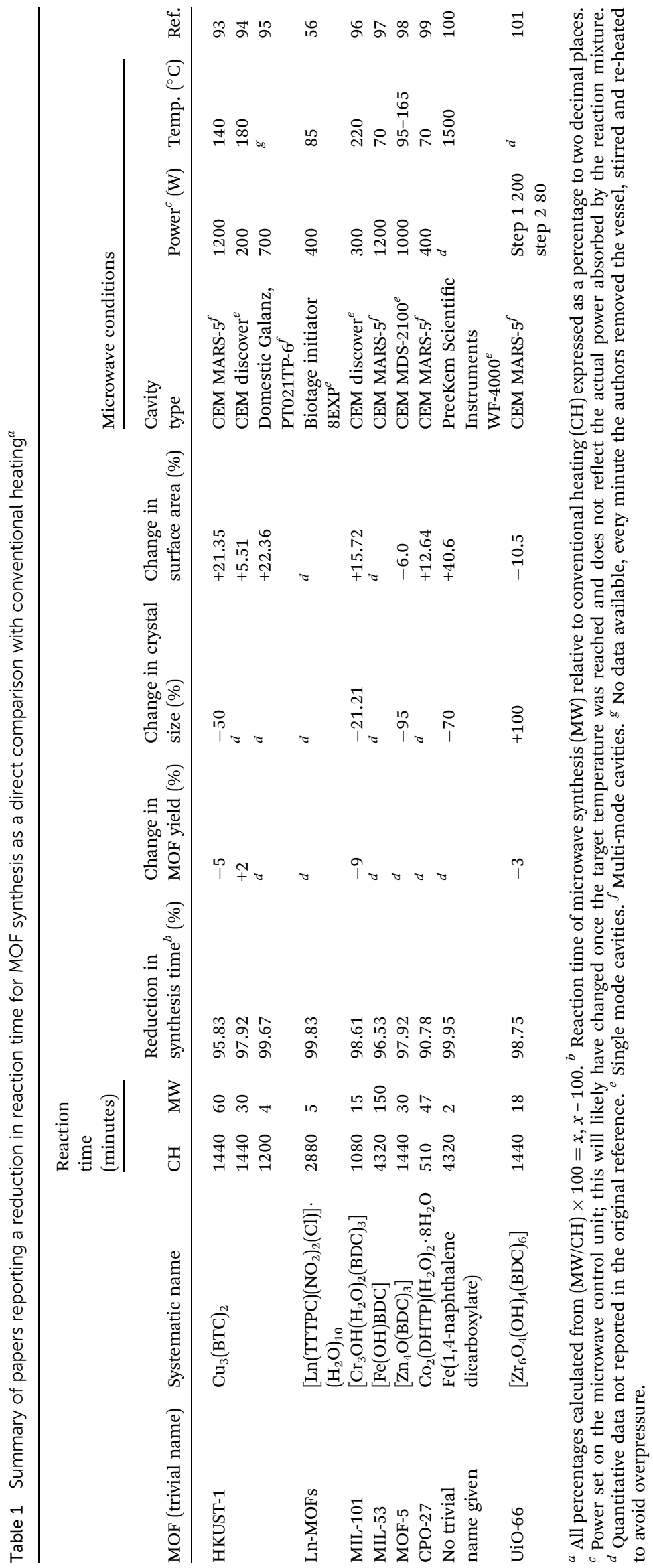


size of MOFs compared to those produced using conventionally heated solvothermal routes. In some cases a $50 \%$ reduction in crystal size is observed (see Table 1 above). ${ }^{93}$ Unlike conventionally heated routes, a narrower crystal size distribution is also exhibited by MOFs produced using microwave-assisted synthesis. $^{25}$ Many research groups have highlighted the importance of particle size and distribution for environmental applications such as chromatographic separations, ${ }^{\mathbf{1 0 2}}$ adsorption, ${ }^{\mathbf{4 2 , 1 0 3}}$ catalysis ${ }^{104-106}$ as well as for making multiferroics. ${ }^{107}$ These results (small crystals and narrow size distribution) have been ascribed to faster kinetics of crystal nucleation and growth owing to hot-spots (or selective heating of components) in the reaction mixture. ${ }^{97}$ It has been hypothesised that the hot-spots give rise to a high concentration of nucleation points and thus a large nuclei to reactant ratio. As the crystals grow on these nuclei, remaining reactant is rapidly consumed, resulting in crystal size reduction. ${ }^{\mathbf{1 0 8}}$ In attempts to quantify the effect of heating source on the crystallisation of MOFs, Haque et al. followed a two-step synthesis of MIL-53(Fe) prepared by ultrasound, conventional, and microwave heating methods using ex situ powder X-ray diffraction (PXRD). ${ }^{97}$ The authors reported increased acceleration factors (calculated from the preexponential factor in the Arrhenius equation) of 14.8 and up

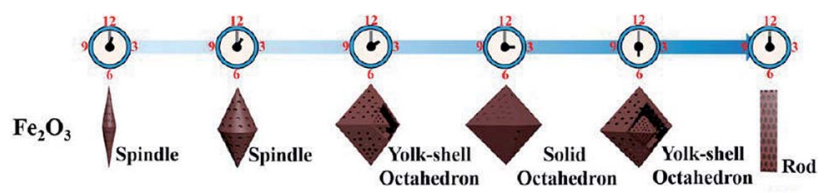

Fig. 2 Morphological progression of iron oxide produced from MIL$53(\mathrm{Fe})$ in a two-step synthesis. Step 1 involved microwave synthesis of the MOF. In step 2, the MOF is calcined. Control of morphology was demonstrated by altering the reaction time in step 1. Reprinted (adapted) with permission from (W. Guo, W. Sun, L.-P. Lv, S. Kong and Y. Wang, ACS Nano, 2017, 11, 4198-4205). Copyright (2017) American Chemical Society. to $\mathbf{5 3 . 1}$ for crystal nucleation and growth, respectively, under microwave conditions (CEM Mars 5 reactor, up to $1200 \mathrm{~W}$, $\left.70{ }^{\circ} \mathrm{C}\right)$ compared to conventional heating $\left(70{ }^{\circ} \mathrm{C}\right) \cdot{ }^{97}$ Ultrasound (VCX 750 ultrasonic generator from Sonics \& Materials, Inc; power varied at fixed reaction temperatures) was also found to have increased acceleration factors (48.7 and 284.2 for the nucleation and crystal growth steps, respectively) compared to conventional heating. ${ }^{97}$ However, in the case of ultrasound synthesis, the mode of acceleration is ascribed to cavitation whereby formation, growth, and instantaneous collapse of bubbles in the reaction mixture generates local hot spots. ${ }^{109}$ Further kinetic studies by ex situ PXRD have also shown significant acceleration of crystal nucleation and growth by microwave heating for a range of MOFs. ${ }^{\mathbf{9 9 , 1 1 0}}$ However, all kinetic studies conducted thus far carry a level of inherent inaccuracy. No consideration is given to the influence of power absorbed by the reaction mixture in the microwave or ultrasound experiments. These approaches also do not take into account the effect of localised microwave heating and simply measure average bulk temperature arising from the differential heating of individual components, coupled with subsequent heat transfer.

In addition to a reduction in crystal size and distribution, many groups have demonstrated the ability to control the crystal size during microwave synthesis. $\mathrm{Ni}$ and Masel were able to fine-tune the crystals of IRMOF-1, -2 and -3 on the submicrometre scale by altering the concentration of the reaction mixtures, more dilute mixtures being preferable. ${ }^{24}$ Bag et al. showed control over crystal size for a series of isostructural lanthanide MOFs by careful manipulation of the reaction time; 5 minute reactions yielded micro-crystals and longer times $(>30$ minutes) gave larger crystals similar in size to the conventionally heated solvothermal route. ${ }^{56}$ Similarly, Li et al. reported control over IRMOF-3 crystal size by varying the synthesis time. ${ }^{111}$ Bunzen et al. ${ }^{112}$ and Liu et al. ${ }^{113}$ demonstrated control over particle size for MFU-4 and a cyclodextrin MOF, respectively, by variation of reaction time and addition of chemical

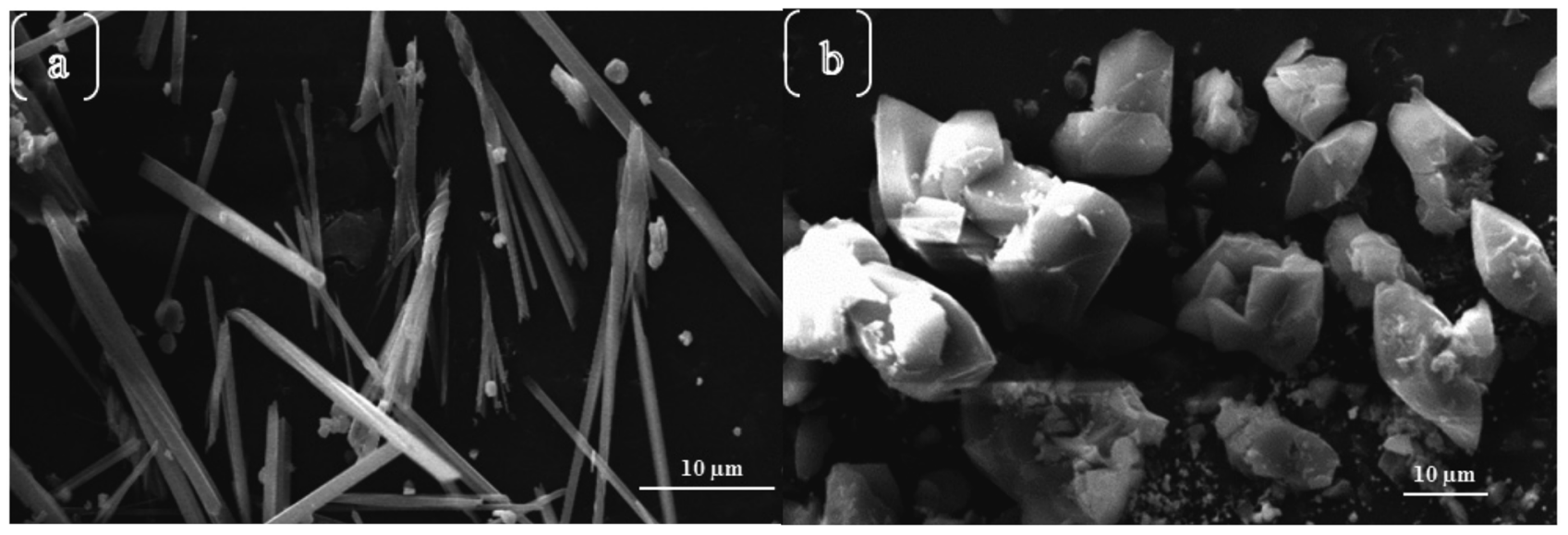

Fig. 3 Morphological differences between microwave (a) and conventionally heated (b) syntheses of a 2-pyridyltetrazole cadmium MOF. ${ }^{119}$ Reprinted from Chinese Journal of Chemistry, A. Chouhan, G. Pilet, S. Daniele, et al., Shape Controllable Preparation of Submicronic Cadmium Tetrazole-Based Metal-Organic Frameworks via Solvothermal or Microwave-Assisted Methods and Their Photocatalytic Studies, with permission from John Wiley and Sons. Copyright 2017 SIOC, CAS, Shanghai \& WILEY-VCH Verlag GmbH \& Co. KGaA, Weinheim. 
modulators to the reaction mixture. Reactions involving addition of a modulator with the same chemical functionality as the linker to the reaction mixture in varying amounts is referred to as coordination modulation. ${ }^{\mathbf{1 1 4}}$ Finally, Laybourn et al. tuned the particle size and distribution of MIL-53(Al) during microwave synthesis by altering the absorbed power at a fixed energy (250-4000 W; $56 \mathrm{~kJ} \mathrm{~mol}^{-1}$, based on water as the solvent) showing smaller crystals and narrower size distributions with increasing absorbed power. ${ }^{25}$

\subsection{Influence of microwave heating on the morphology of MOFs}

In most instances of microwave synthesis of MOFs, the morphology (i.e. crystal or particle shape) of products is the same as those produced using conventionally heated solvothermal methods. However, few examples of differences in morphology have been reported. Taylor et al. showed a change from spiral rods $(1-2 \mu \mathrm{m})$ to smaller (300 $\mathrm{nm}$ ) block-like particles for the room temperature and microwave-assisted syntheses, respectively. ${ }^{115}$ Using microwave-assisted coordination modulation (for further explanation see Section 3.3), Sakata et al. altered the morphology of $\mathrm{Zn}_{2}(\mathrm{ndc})_{2}$ (dabco) (ndc: 1,4naphthalenedicarboxylate; dabco: 1,4-diazabicyclo[2,2,2] octane) from large micron-sized cubic crystals to nano-sized rods by changing the quantity of modulator added to the reaction mixture. ${ }^{114}$ Guo et al. demonstrated morphological control over MIL-53(Fe), and the resultant iron oxide nanostructures produced from the calcined MOF, by varying the reaction time in the MOF synthesis step. ${ }^{116}$ Reaction times of 0.5 and 2 hours gave $1.5 \mu \mathrm{m}$ long spindles and shorter, fatter spindles, for the iron oxide materials respectively (see Fig. 2). ${ }^{\mathbf{1 1 6}}$ At longer times, the microwave reaction led to the production of yolk-shell octahedra with increasing size until 12 hours where large rod structures were observed (Fig. 2). ${ }^{116}$ In all cases PXRD confirmed production of MIL-53(Fe) in the microwave-synthesis step $^{\mathbf{1 1 6}}$ except for the 12 hour reaction which produced a different, though previously reported phase. ${ }^{117}$

Finally, Chouhan et al. reported aggregated rhomboidal crystals and thin needle crystals for a MOF based on 2-pyridyltetrazole and zinc produced by conventional and microwave heating methods, respectively; ${ }^{118}$ and rhomboidal (Fig. 3a) and bundled fibrous (Fig. 3b) nano-sized crystals for the conventional and microwave synthesis of the isostructural cadmium analogue, respectively. ${ }^{\mathbf{1 1 9}}$

Interestingly, although PXRD analyses of the zinc and cadmium 2-pyridyltetrazole MOFs indicated identical crystal structures, the materials produced via microwave and conventional methods exhibited subtly different properties (BET surface areas, UV-vis absorption, and luminescence). ${ }^{\mathbf{1 1 9}}$ As a result of these differences, the microwave products performed better in the studies of photo-catalytic degradation of methylene blue, which the authors attributed to the higher surface area and therefore more accessible reactive sites in the microwave-synthesised MOFs. ${ }^{119}$ Although changes in morphology as a result of microwave heating have been reported, the effect of microwave heating on the growth mechanism is yet to be established.

\subsection{Influence of microwave heating on the surface area of MOFs}

The surface area varies largely for any given MOF. For example, MIL-53(Al) from commercial sources (tradename: Basolite ${ }^{\circledR}$ A100) is supplied with a surface area ranging from 1100 to $1500 \mathrm{~m}^{2} \mathrm{~g}^{-1} \cdot{ }^{120}$ Many factors are known to affect the surface

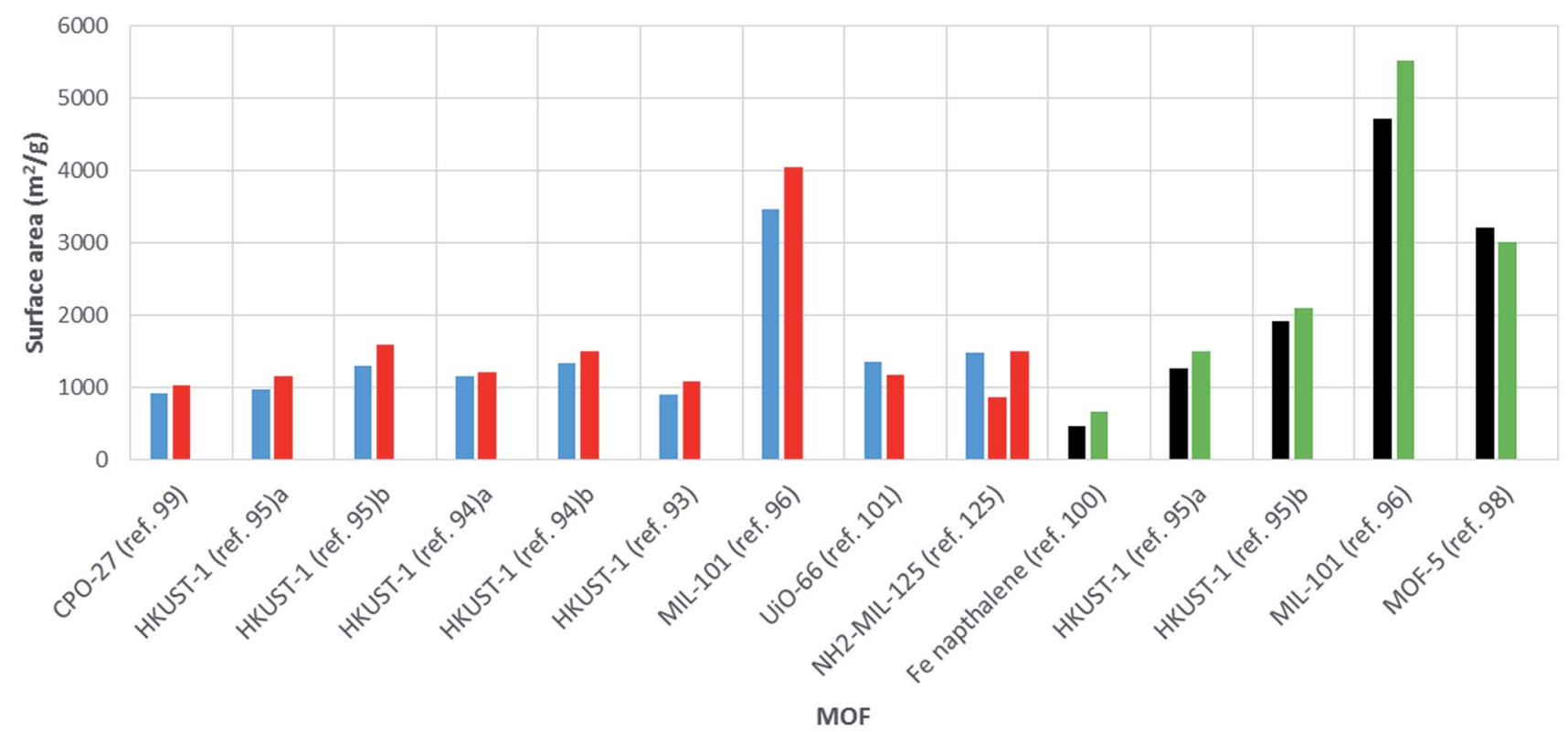

Fig. 4 Bar chart showing comparative surface areas between MOFs prepared using microwave (red, BET; green, Langmuir) and conventionally heated solvothermal (blue, BET; black, Langmuir) synthesis. Ref. $95^{\mathrm{a}} \mathrm{MOF}$ activated by dissolution in $\mathrm{CHCl}_{3}$. Ref. $95^{\mathrm{b}} \mathrm{MOF}$ activated using supercritical carbon dioxide. Synthesis conducted in ethanol and water (ref $94^{\mathrm{a}}$ ) and DMF (ref $94^{\mathrm{b}}$ ). 
area, including solvent choice, quantity of solvent in the reaction mixture, ratio of metal to linker, choice of metal salt and reaction temperature. ${ }^{\mathbf{1 2 1 - 1 2 3}}$ Therefore, in order to make a fair assessment of the effect of heating method (conventional solvothermal vs. microwave) on the surface area, comparison between reactions involving the same chemical conditions are required. In these cases, microwave synthesis of MOFs has generally been shown to give products with higher surface areas than those produced via conventional heating routes (see Table 1 and Fig. 4).

In a comparative study, Khan and Jhung found HKUST-1 synthesised using microwave heating to have a larger surface area and pore volume than the conventionally heated solvothermal product $\left(1080 \mathrm{~m}^{2} \mathrm{~g}^{-1}\right.$ and $0.39 \mathrm{~cm}^{3} \mathrm{~g}^{-1}$ compared to $890 \mathrm{~m}^{2} \mathrm{~g}^{-1}, 0.32 \mathrm{~cm}^{3} \mathrm{~g}^{-1}$, respectively, see Table 1)..$^{93}$ Increased surface areas and pore volumes for MOFs produced by microwave heating compared to conventional heating have also been reported for MIL-101 ${ }^{\mathbf{9 6}}$ and further examples of HKUST-1 ${ }^{\mathbf{9 4 , 9 5}}$ values are given in Table 1 . The largest increase in surface area with microwave heating to date was reported by Lou et al. for a 1,4-naphthalene di-carboxylate based iron MOF synthesised using a WF-4000 microwave reactor (PreeKem Scientific Instruments). ${ }^{\mathbf{1 0 0}}$ In this case a surface area increase of around $40 \%$ was observed (see Table 1 ). ${ }^{\mathbf{1 0 0}}$

An increase in surface area for microwave-synthesised MOFs has been attributed to the production of smaller crystals compared to those resulting from conventional heating methods. ${ }^{99}$ There are many cases where nano-sized crystals have been found to exhibit greater surface areas than larger MOF crystals. ${ }^{124}$ However, few examples of reduced surface areas for MOFs produced by microwave heating have been reported. These include MOF-5, ${ }^{98}$ UiO-66 ${ }^{101}$ and MIL-53(Al) ${ }^{25}$ where the reduction in surface area was attributed to trapping of oxidised reaction solvent in the pores of the $\mathrm{MOF},{ }^{98}$ a reduction in linker defects, ${ }^{\mathbf{1 0 1}}$ and thermally-induced deterioration of crystal quality at high absorbed powers, ${ }^{25}$ respectively. Finally, Kim et al. reported both larger and smaller surface areas for MIL-125 and $\mathrm{NH}_{2}$-MIL-125 materials produced using microwave heating (power and reaction time varied) compared to conventionally heated reactions with no clear trend. ${ }^{125}$ This result suggests that any effect microwave heating has on surface area is dependent on the specifics of the particular synthesis (reactant ratios, solvent systems).

\subsection{Summary}

In Section 3 we have shown that microwave synthesis is an extremely promising route for MOFs as it potentially offers shorter reaction times, and therefore, lower energy consumptions, control over crystallite size and morphology, and can also produce MOFs with higher surface areas than those produced by conventional solvothermal methods. However, despite the huge activity in this area, gaps in fundamental understanding are still prevalent. For example, the underlying effect of microwave heating on morphology, crystal growth and surface area are still not fully understood. Additionally, many of the reported studies use the average temperature of the reaction

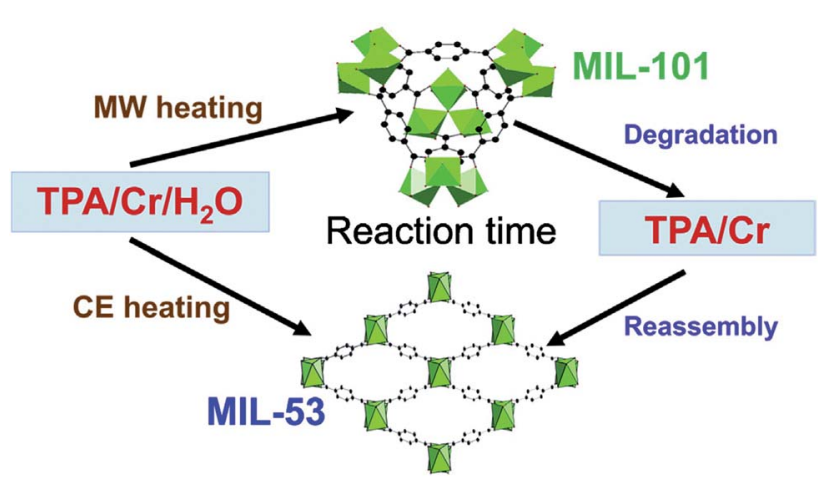

Fig. 5 Schematic representation for the formation of two MOF phases (MIL-101 and MIL-53) from reaction between $\mathrm{CrCl}_{3} \cdot 6 \mathrm{H}_{2} \mathrm{O}$ and $\mathrm{H}_{2} \mathrm{BDC}$ in water using microwave and conventional heating. Reprinted from Coordination Chemistry Reviews, 285, N. A. Khan, S. H. Jhung, Synthesis of metal-organic frameworks (MOFs) with microwave or ultrasound: rapid reaction, phase-selectivity, and size reduction, 1123, Copyright (2015), with permission from Elsevier.

mixture as a key indicator for microwave heating. In order for the area to move forward the effect of microwave parameters such as electric field strength and distribution and the dielectric properties must be considered in order to determine if the bulk synthesis mixture was heated by microwave energy.

\section{Microwave synthesis of new MOFs and MOF-hybrids}

\subsection{Background}

Microwave heating is advantageous for MOF discovery owing to the ability to screen many reaction conditions in a short timeframe. Additionally, selective heating offers the potential to produce new MOF structures through kinetically driven reactions. This section discusses the use of microwave technology in the preparation of new MOFs and MOF-hybrids.

\subsection{Phase-selective synthesis of MOFs}

MOFs can exhibit multiple phases; that is different arrangements of the same metal nodes and linkers, resulting in fundamentally different crystal structures. In some instances up to 5 separate structural phases have been produced from the same reactants. ${ }^{\mathbf{1 2 6 , 1 2 7}}$ Different MOF phases often exhibit different properties, notably surface area, therefore production of specific phases is essential for targeting precise properties. ${ }^{128}$ Synthesis of specific MOF phases can be achieved through control of $\mathrm{pH}$ and temperature, by templating and by microwave heating. ${ }^{21}$ For example, Khan and Jhung ${ }^{28}$ investigated phase selective synthesis of two MOFs, namely MIL-53(Cr) and MIL-101(Cr), from aqueous reaction mixtures of chromium chloride hexahydrate and terephthalic acid $\left(\mathrm{H}_{2} \mathrm{BDC}\right) .{ }^{28}$ The reaction mixtures were heated to $210^{\circ} \mathrm{C}$ under autogenous pressure using either conventional or microwave heating for specific time intervals (daily and hourly, respectively) and the ratio of phases was determined by ex situ PXRD analysis. $^{28}$ In the early stages of reaction, $<1$ day for 
Table 2 Summary of hybrid MOF materials produced using one-pot synthesis and microwave heating

\section{Classification of}

material produced

Core-shell hybrid Inorganic composites$$
\text { posites }
$$

Entrapped molecules/ 'doped' hybrid MOFs
Details

MIL-53-Cr/V
Silica/HKUST-1
Alumina/HKUST-1
Silica (MCM-41)/HKUST-1
Spiropyran incorporation in
thin film JUC-120
Keggin phosphotungic acid
doped MIL-101
IRMOF-3 doped with silver
nanoparticles
Cu-BDC/reduced graphene
oxide composite as a precursor
for hybrid metal oxide

conventional and $<3$ hours for microwave heating, the kinetically favourable MIL-101(Cr) product was dominant. ${ }^{28}$ Longer reaction times ( $>3$ hours) resulted in greater quantities of the thermodynamically favourable MIL-53(Cr) product. $^{28}$ The authors proposed a mechanism for the formation of these two phases; MIL-101 forms first, disassembles, re-assembling to form the MIL-53 phase, as shown in Fig. 5. ${ }^{28,129}$ Exclusive synthesis of the MIL-101(Cr) phase (termed 'phase-pure') was achieved using microwave heating with reaction times of 1 hour. ${ }^{28}$

Further work by Khan et al. focused on a series of three frameworks based on aluminium metal nodes and trimesic acid, namely MIL-96(Al), MIL-100(Al) and MIL-110(Al). ${ }^{128}$ Alteration of the reaction time and $\mathrm{pH}$ during microwave heating enabled isolation of the separate phases; MIL-110(Al) $<2 \mathrm{~h}$, 2.3 M equivalents of base; MIL-100(Al) $<2$ h, $2.3 \mathrm{M}$ equivalents of nitric acid and reactions conducted above 2 hours afforded the thermodynamically stable MIL-96(Al) phase. ${ }^{\mathbf{2 8}}$ Interest-

ingly, the authors identified a downward trend in porosity with BET surface areas of 1056, 639 and $216 \mathrm{~m}^{2} \mathrm{~g}^{-1}$, for MIL-100, MIL-110 and MIL-96, respectively, indicating that more porous structures are inherently less thermodynamically stable. ${ }^{128}$ Finally, during the microwave synthesis of MIL-77 (a cubic nickel glutarate MOF, previously prepared by Guillou et $a{ }^{\mathbf{1 3 0}}$ ), Jhung and co-workers discovered a new tetragonal phase. ${ }^{26}$ Alteration of the reaction conditions showed that the cubic phase preferentially forms at low $\mathrm{pH}$, low temperature and especially under conventional heating whereas the tetragonal phase is obtained favourably at high $\mathrm{pH}$, high temperature and particularly using microwave heating (Mars-5 CEM multimode reactor, power input was varied at different stages of the reaction). ${ }^{26}$ This result was unexpected as previous reports had shown the denser tetragonal phase to be thermodynamically favourable and the less dense cubic phase to be kinetically favourable and so one would expect the cubic and tetragonal phases to dominate in microwave and conventionally heated
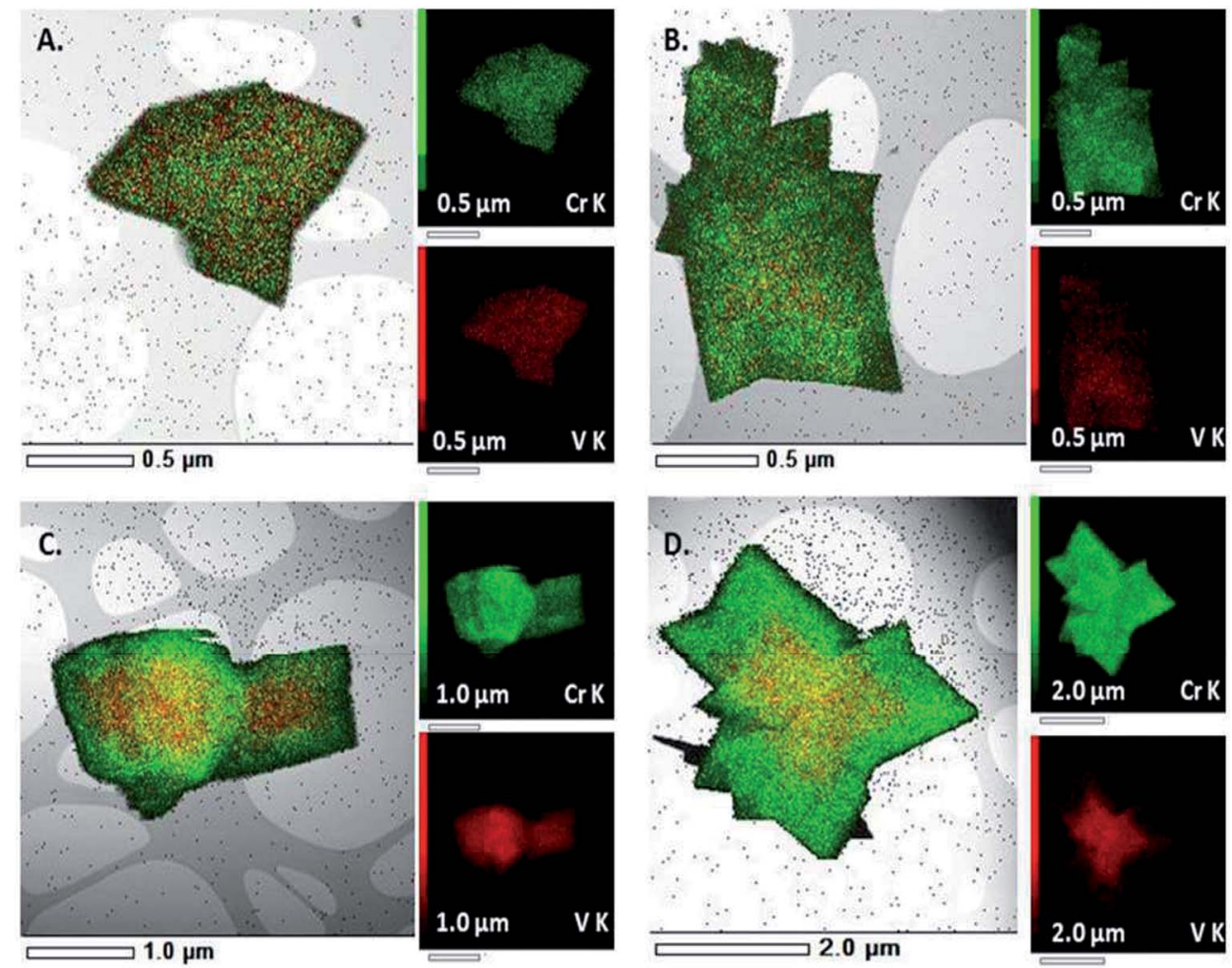

Fig. 6 EDX spectroscopy mapping of a homogenous ( $A$ and B) and "egg yolk" (C and D) mixed metal MIL-53(Cr/V) MOF synthesised by conventional and microwave heating, respectively. ${ }^{135}$ Reproduced from ref. 135 with permission from the Royal Society of Chemistry. 
reactions, respectively. ${ }^{26}$ The authors hypothesised the formation of the denser tetragonal phase under microwave heating to be the result of changes in crystallisation rates for the two phases. $^{26}$

\section{3. "One pot" synthesis of MOF hybrids}

In chemistry, a one-pot synthesis involves carrying out successive chemical reactions in one reactor. This strategy is often employed to improve the efficiency of reactions as multiple work-up steps are avoided. In MOF chemistry, one-pot synthesis is often used to prepare MOF-hybrids or MOFs with additional functionality as the porous structure can be further functionalised by the secondary reaction. Examples of one-pot microwave-assisted syntheses of MOF hybrids include; MOF- silica $^{\mathbf{1 3 1 , 1 3 2}}$ and MOF-alumina ${ }^{\mathbf{1 3 1}}$ composites; a photochromic indium trimesate (trivial MOF name, JUC-120) hybrid film produced by entrapping guest molecules within the framework; $;^{133}$ a catalyst for alcoholysis of styrene oxide produced by doping MIL-101(Cr) with phosphotungstic acid; ${ }^{\mathbf{1 3 4}}$ and a heterogeneous catalyst for microwave heated organic coupling reactions comprising of IRMOF-3 doped with silver nanoparticles synthesised from the MOF precursor solution and silver nitrate. ${ }^{\mathbf{1 1 1}}$ In the latter example the sizes of silver nanoparticles were controlled by altering the reaction time. ${ }^{\mathbf{1 1 1}}$ All of these reports are summarised in Table 2.

Recently Depauw et al. used microwave heating to prepare a mixed metal MIL-53 MOF via a one-pot reaction containing a mixture of chromium and vanadium salts and $\mathrm{H}_{2}$ BDC linker. ${ }^{135}$ Under conventionally heated solvothermal conditions

Table 3 Summary of PSM of MOFs using microwave heating

\begin{tabular}{|c|c|}
\hline Type of PSM & Details \\
\hline $\begin{array}{l}\text { Incorporation of catalytic } \\
\text { nanoparticles }\end{array}$ & $\begin{array}{l}\text { MIL-101@Pd, MIL-101@Cu and } \\
\text { MIL-101@Pd/Cu (bimetallic } \\
\text { nanoparticles incorporated) } \\
\text { ScBTC@Pd } \\
\text { MIL-101@Cu }\end{array}$ \\
\hline $\begin{array}{l}\text { Incorporation of catalytically active } \\
\text { nanoparticles }\end{array}$ & $\begin{array}{l}\text { UiO-66@Pd } \\
\text { MIL-101@Cu and MIL-101@Ni } \\
\text { MIL-101@ } \mathrm{Fe}_{2} \mathrm{O}_{3}\end{array}$ \\
\hline $\begin{array}{l}\text { Incorporation of graphene oxide } \\
\text { Linker functionality modification }\end{array}$ & $\begin{array}{l}\text { ZIF-8 derived } \mathrm{ZnO} \text { with } \\
\text { incorporated graphene oxide } \\
\text { UiO-66- } \mathrm{Br} \rightarrow \text { UiO-66-CN }\end{array}$ \\
\hline & $\begin{array}{l}\text { De-protection of an amine } \\
\text { functionalised with tert- } \\
\text { butoxycarbonyl (Boc) group IRMOF- } \\
74(\mathrm{Mg}) \\
\text { MIL-101-NH } \\
\text { MIL-68- } \mathrm{NH}_{2} \rightarrow \text { MIL-101-peptide } \\
\text { UiO-66- } \mathrm{NH}_{2} \rightarrow \text { UiO-68-peptide } \\
\text { MIL-53-NH } \mathrm{NH}_{2} \text { functionalised with an } \\
\text { alkyl halide } \\
\text { IRMOF-74-III }\end{array}$ \\
\hline
\end{tabular}

De-protection of IRMOF-74-III-Boc to give the primary amine MIL-101 MIL-101(Fe), MIL-101(Al), MIL100(Cr), UiO-66, MIL-88B(Cr), MIL53(Al)

MIL-53

Cation exchange

$\mathrm{Ni}-\mathrm{BTC} \rightarrow \mathrm{Ni} / \mathrm{Cu}-\mathrm{BTC}$

UiO-66 $\rightarrow$ UiO-66(Zr/Ti)

Ni-BTC to mixed metal Ni/Sn-BTC

Synthetic precursor to hybrid metal oxide

$$
\begin{aligned}
& \text { MIL-100 } \rightarrow \text { magnetic } \mathrm{Fe}_{2} \mathrm{O}_{3} / \mathrm{C} \\
& \text { composite } \\
& \text { MIL-53 } \rightarrow \text { magnetic } \mathrm{Fe}_{2} \mathrm{O}_{3} / \mathrm{C} \\
& \text { composite }
\end{aligned}
$$

Prussian blue: $\mathrm{Zn}\left(\mathrm{CO}_{3}\right)$
Comment

Ref.

Catalytic oxidation of $\mathrm{CO}$

140

Cross coupling reactions

141

Catalytic reduction of nitro-

142

aromatics

Cross coupling reactions

143

Augmented $\mathrm{CO}_{2}$ storage

144

Catalytic oxidation of alcohols and

145

alkenes

Photo-catalytic degradation of

methylene blue

$90 \%$ yield, route to otherwise

unobtainable linker functionality

146

147

148

Up to tetra-amino acids grafting

onto the linkers without

racemization of the amino acids

Catalytic synthesis of cyclic

carbonates

Multivariate in pore tri-peptide

functionality

Carbon capture

Chromatography

153

Solid phase extraction of penicillin

Base for production of hybrid metal

oxides

Photocatalysis

Base for production of hybrid metal oxides

Ionothermal synthesis with doped zinc chloride

Ionothermal synthesis with doped zinc chloride, for dye removal and degradation

Precursor for a porous $\mathrm{ZnO} / \mathrm{ZnFe}_{2} \mathrm{O}_{4}$ composite 
a homogenous framework was produced, however microwave heating led to the formation of an "egg yolk" structure comprising of a $\mathrm{Cr} / \mathrm{V}$ core surrounded by a pure chromium MIL53 shell as determined by energy-dispersive X-ray (EDX) spectroscopy mapping shown in Fig. $6 .{ }^{\mathbf{1 3 5}}$

\subsection{Post-synthetic modification of MOFs}

Microwave heating has also been used for the post-synthetic modification (PSM) of MOFs, whereby a pre-formed MOF is altered. PSM is a particularly important technique as it enables further enhancement and fine-tuning of MOF properties for a wide range of applications through inclusion of alternative chemical species/functionalities. ${ }^{\mathbf{1 3 7 - 1 3 9}}$ Post synthetic modification can be categorised into several types, including modification of the linkers (without changing the structure of the MOF) or metal nodes, incorporation of additional chemical species (also called doping, often into the pores of the MOF), or modification of the whole MOF structure. Examples of PSM facilitated by microwave heating are now discussed and a summary is presented in Table 3 .

An example of PSM by doping was reported by El-Shall et $a{ }^{\mathbf{1 4 0}}$ In their work a catalyst for the oxidation of CO gas was prepared by doping MIL-101 with metallic and bimetallic nanocrystals. ${ }^{140}$ During the PSM step, metal salts of palladium and copper where allowed to diffuse into the pores of MIL-101 before addition of a hydrazine hydrate reducing agent. ${ }^{\mathbf{1 4 0}}$ This was followed by a 2 minute microwave reaction to yield the final MOF@nanoparticle materials. ${ }^{\mathbf{1 4 0}}$ Several examples of PSM involving the MOF linker have been reported, in this case an exposed pendant functional group on the linker undergoes chemical reaction. For instance, Bonnefoy et al. successfully grafted oligopeptides onto the linker of 3 MOFs using microwave heating. ${ }^{149}$ The authors highlighted the diversity of peptide chemistry as a potential route to a large library of MOFoligopeptide materials with potential applications in sensing, catalysis and separation. ${ }^{149}$ It is important to note that the ability to produce MOFs with numerous different pendant functional groups on the linker is particularly powerful as it is conceivably possible to perform countless reactions to augment MOFs using this method of PSM. A final notable example of PSM by microwave heating involves preparation of MOF-polymer monoliths reported by Lin et al. ${ }^{154}$ The various MOFs (see Table 3 'MOF-polymer monoliths' for exact details) were suspended in a monomer mixture, loaded into a column and then polymerised by microwave heating to give the MOF-polymer monoliths. ${ }^{154}$ The monoliths were tested for their ability to extract and recover penicillin-type compounds in solid phase extraction, with excellent results. ${ }^{162}$

\subsection{Summary}

From the many examples discussed in Section 4 and summarised in Tables 2 and 3, it is clear that microwave heating is an effective method for the production of new MOFs and MOF hybrids by phase-selective or one-pot synthesis or through PSM. However, as identified in Section 3 of this paper, there is little understanding of the mechanisms of microwave heating. In particular the effect of microwave energy on MOF crystallisation is yet to be determined.

\section{Towards industrial scale microwave synthesis of MOFs}

\subsection{Background}

The diverse and tuneable properties of MOFs offer immense opportunities for economic and environmental impact; for example in the field of ambient pressure $\mathrm{CO}_{2}$ capture, ${ }^{163,164}$ an industry which is estimated to be worth between $\$ 128$ billion and $\$ 221$ billion by $2030 .{ }^{165}$ However, current state of the art in industrial manufacture has restricted widespread adoption of MOFs for commercial applications, as at scale they deliver poor quality materials, whilst incurring high energy and capital costs, meaning that many applications are not economically viable. The production of MOFs at large scales is hindered by a combination of chemical, environmental and engineering challenges including; dependence on high temperatures and pressures to give solvothermal synthesis conditions; use of large quantities of toxic, corrosive and highly flammable chemicals; production of acidic by-products, long times required for crystal growth; cost and availability of large scale reaction rigs; and energy requirements. ${ }^{22}$ Additional challenges also exist in materials handling, such as; heterogeneous reaction conditions, mixing requirements, reactions that form precipitates; and separation of products after synthesis.

In order to address these challenges, microwave reactions under continuous flow conditions have recently been developed. This production route has several advantages; the combination of rapid microwave heating and high surface areato-volume ratio for a reaction mixture in a flow reactor leads to improvements in heat and mass transfer and thus significant reduction in synthesis time; typically less solvent is required; process intensification leads to less energy consumption and safer implementation of harsh reaction conditions; improved control over the synthesis parameters allows faster optimisation of reactions to give reproducible MOF products of high quality; and continuous flow reactors are more scalable and often greener compared to batch systems. ${ }^{22}$

This section focuses on recent research efforts involving the production of MOFs beyond the laboratory scale using microwave technology. Current microwave systems for MOF synthesis on the gram to kilogram scale are presented and their advantages and limitations are discussed. Additionally, the successful development of industrial scale microwave reactors in other sectors is described in order to highlight important considerations and learnings transferrable to the development of an industrial scale microwave process for the synthesis of MOFs. Finally, the economic and environmental implications of industrial scale microwave reactors are discussed.

\subsection{Current efforts in scaling-up MOF synthesis using microwave heating}

The first continuous flow microwave reactor for the synthesis of MOFs was reported in 2015. ${ }^{166}$ The pioneering work by 
Table 4 Summary of parameters used in continuous flow microwave reactors for synthesis of MOFs

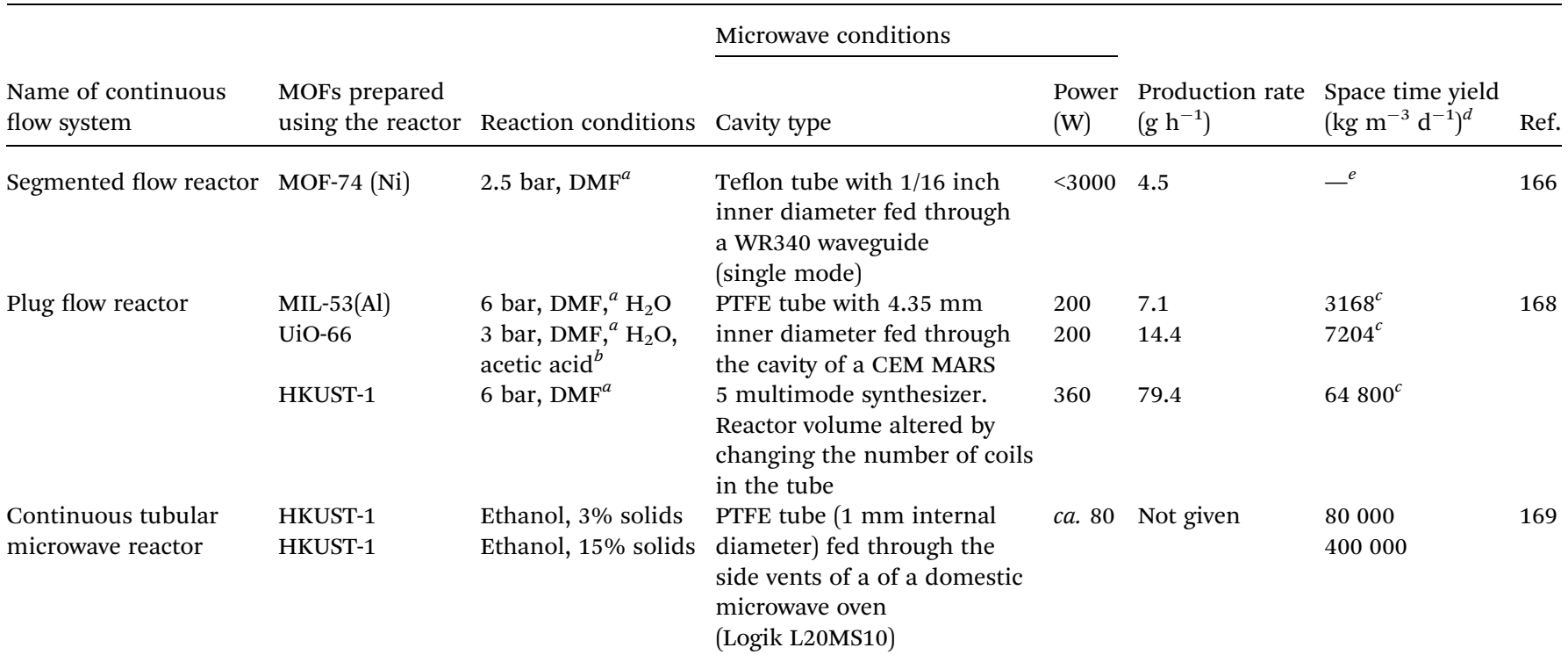

${ }^{a} \mathrm{DMF}=N, N$-dimethylformamide. ${ }^{b}$ Acetic acid was used as a modulator. ${ }^{c}$ Based on a $53 \mathrm{~mL}$ microwave heated zone and production rate in $\mathrm{g} \mathrm{h}^{-1}$ (in the adjacent column). ${ }^{d}$ Number of hours equivalent to 1 day is variable, depending on the source, and not formally given. ${ }^{e}$ STY not stated, $80-$ $90 \mathrm{~g} \mathrm{~L}^{-1} \mathrm{~h}^{-1}$ given instead.

Albuquerque et al. involved laboratory scale preparation of MOF-74(Ni) using a gas liquid segmented flow reactor. ${ }^{166}$ Gas liquid segmented flow was used to improve mixing and to prevent blockages in the reactor. ${ }^{166}$ The reactor comprises a 1/16 inch tube fed through two sections; a microwave heated zone (see Table 4 for specific details) used for nucleation, and a conventionally heated oil bath zone for crystal growth, as shown in Fig. 7. ${ }^{166}$ Both sections were found to be necessary for MOF production as broad peaks were observed in the PXRD patterns of MOF-74(Ni) prepared without the oil bath zone. ${ }^{166}$ The authors reported high conversion of reagents ( $c a .96 .5 \%)$ and space time yields (STY) of $\left(\sim 90 \mathrm{~g} \mathrm{~h}^{-1} \mathrm{~L}^{-1}\right.$ or $720 \mathrm{~kg} \mathrm{~m}^{-3} \mathrm{~d}^{-1}$, where 1 day is equivalent to 8 hours) ${ }^{166}$ a significant improvement on the conventional heated batch process (STY of $\left.28.5 \mathrm{~g} \mathrm{~L}^{-1} \mathrm{~h}^{-1}\right){ }^{167}$

Building upon their batch process involving simultaneous heating of multiple discrete vessels containing MOF reaction in a multimode microwave reactor (CEM MARS 5 synthesizer), ${ }^{101}$ Taddei et al. investigated the continuous flow microwave synthesis of three MOFs, namely UiO-66, HKUST-1 and MIL$53 .{ }^{168}$ The reactor comprises a coiled PTFE tube fed through a CEM MARS 5 synthesizer. ${ }^{168}$ The volume of the microwave section of the reactor was altered by changing the number of coils in the tube. ${ }^{168}$ Downstream of the microwave heated section, the tube is introduced into a custom-built pressurised 'collector' made of glass, as shown in Fig. $8 .{ }^{168}$ The collector negates the need to flow slurries containing reactants and products through the back pressure regulator, preventing blockages in the reactor. ${ }^{168}$ Specific reaction conditions (pressures, solvent systems) and microwave parameters are given in Table 4, above. STYs of $3618,7204,64800 \mathrm{~kg} \mathrm{~m}^{-3} \mathrm{~d}^{-1}$ for MIL53, UiO-66, and HKUST-1, respectively were achieved. ${ }^{168}$
Using the same reactor (Fig. 8), ${ }^{168}$ Taddei et al. investigated the crystallisation of UiO-66 using high-resolution powder X-ray diffraction by placing the outlet tube (coming out of the microwave heated section) in the focus of the X-ray beam. ${ }^{170}$ This experimental set-up enabled in situ monitoring of the reaction after microwave heating had taken place. The effect of varying quantities of water and acetic acid modulator in the

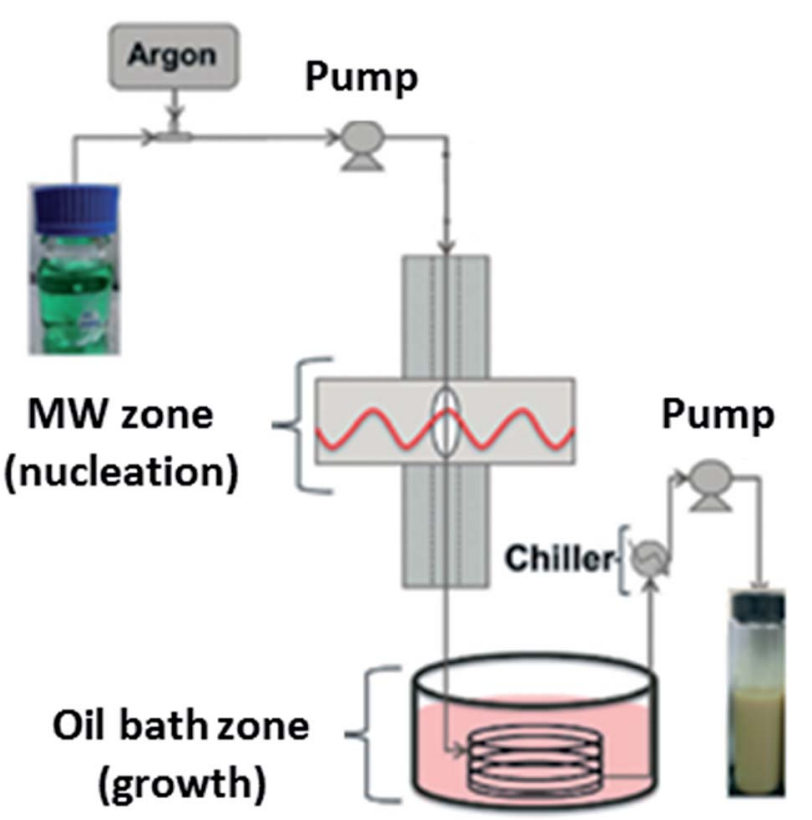

Fig. 7 Schematic diagram of the gas liquid segmented continuous flow reactor for synthesis of MOF-74(Ni) developed by Albuquerque et al. ${ }^{166}$ Reproduced from ref. 166 with permission from the Royal Society of Chemistry. 


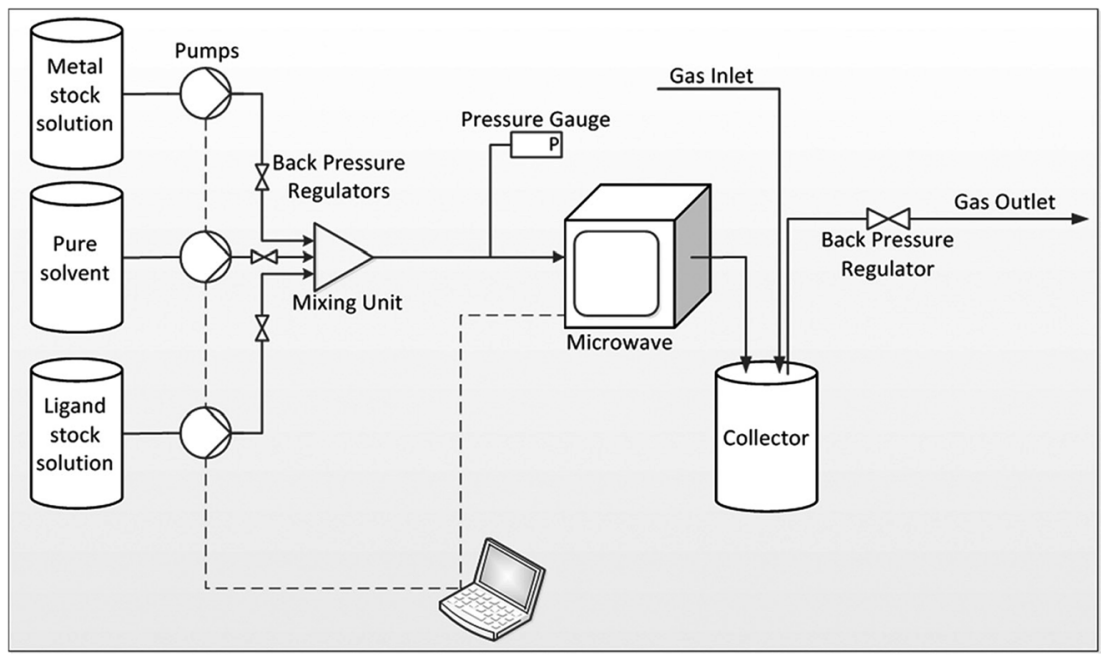

Fig. 8 Schematic diagram of the plug flow microwave reactor developed by Taddei et al. ${ }^{168}$ Reprinted from Chemistry A European Journal, M. Taddei, D. A. Steitz, J. A. van Bokhoven, et al. Continuous-Flow Microwave Synthesis of Metal-Organic Frameworks: A Highly Efficient Method for Large-Scale Production, with permission from John Wiley and Sons. Copyright 2016 WILEY-VCH Verlag GmbH \& Co. KGaA, Weinheim.

reaction mixture on the yield and crystallite size of UiO-66 was investigated over a range of residence times. No consideration was given to the effect of absorbed microwave energy on the reaction. A constant power of $280 \mathrm{~W}$ was applied in all experiments, therefore the reaction mixtures were subjected to varying amounts of microwave energy depending upon the flow rate. Results showed the rate of product formation, yield and crystallite size to be highly dependent on the water/acetic acid ratio and age of metal salt stock solution. ${ }^{170}$

Most recently, McKinstry et al. reported the continuous flow microwave synthesis of HKUST-1 using a PTFE tube $(1 \mathrm{~mm}$ internal diameter) fed through the side vents of a domestic microwave oven (Logik L20MS10, $800 \mathrm{~W}$ ) ${ }^{169}$ The authors highlighted that alterations to the microwave cavity casing were avoided for safety reasons, ${ }^{169}$ however, it is extremely important to note that microwave leakage may still occur even without modification. As electromagnetic wave is attenuated by the reaction mixture (i.e. the amplitude of the electric field diminishes owing to absorption of the field by the reaction mixture, see Section 2 for further details) it is possible for the wave to be small enough to pass along the tube and out of the microwave cavity. Consideration and mitigation of microwave leakage is discussed further in Section 5.3. Using their continuous flow microwave system, McKinstry et al. investigated the effect of varying concentration (reported as \% of solids) and residence times on the yield and surface area of HKUST-1 with a constant power input of $80 \mathrm{~W}$; a summary of these results is given in Table $4 .{ }^{169}$ As the production rate was found to greatly affect the surface area (a key indicator of MOF quality), the authors used surface area production rates (SAPRs, the amount of surface area of MOF produced per reactor volume and time, $\mathrm{m}^{2}$ per $\mathrm{m}^{3}$ per day, where a day is equivalent to 24 hours) ${ }^{169}$ to compare between experiments and other reported methods of production. A residence time of 6 minutes with 3\% solids gave an STY of $2700 \mathrm{~kg} \mathrm{~m}^{-3} \mathrm{~d}^{-1}$ with an SAPR of $5.2 \times 10^{6} \mathrm{~m}^{2} \mathrm{~m}^{-3} \mathrm{~d}^{-1}$ (BET surface area of $\left.1930 \mathrm{~m}^{2} \mathrm{~g}^{-1}\right)$. A residence time of 13 seconds and solids of 3 and $15 \%$ gave STYs of 80000 and $400000 \mathrm{~kg} \mathrm{~m}^{-3} \mathrm{~d}^{-1}$, respectively. ${ }^{169}$ However, in both cases a decrease in surface area was observed; 1550 and $600 \mathrm{~m}^{2} \mathrm{~g}^{-1}$ (corresponding to an SAPR of $240000 \times 10^{6} \mathrm{~m}^{2} \mathrm{~m}^{-3} \mathrm{~d}^{-1}$ ) for 3 and $15 \%$ reaction solids, respectively. ${ }^{169}$ Although an STY of $400000 \mathrm{~kg} \mathrm{~m}^{-3} \mathrm{~d}^{-1}$ is, to the best of our knowledge, the highest value for any MOF produced to-date via any synthesis method, a significant reduction in surface area indicates production of poor quality MOF. The tradeoff between product quality and rapid, scalable bulk production of MOFs is an important consideration for industrial manufacture.

\subsection{Development of industrial scale microwave reactors; important factors to consider}

Scaling-up microwave systems from the laboratory to industry requires a multi-disciplinary approach and many factors must be considered from a materials processing, microwave design chemical, environmental and economic perspective. It is beneficial to transfer key learning outputs from successful development of industrial scale microwave reactors in other processing sectors. An example of this is the microwave treatment of ores for the mining industry, work which has led to the largest mass throughput microwave processing systems ever developed. In their work, Buttress et al. ${ }^{171}$ and Batchelor et al. ${ }^{172}$ demonstrated the necessity for understanding the fundamental parameters required for designing microwave systems capable of a stable and reliable treatment that also meets with occupational health and safety (OHS) and electromagnetic compatibility (EMC) regulations. These parameters (discussed in this paper in Section 2) include (i) dielectric properties, defining the efficiency of power coupling and distribution of the electric field within the heating cavity; (ii) penetration depth and relationship with reactor design and specification; (iii) power density in the heated phase, which is a direct function of the dielectric loss, the applied frequency and the electric field strength. All of 
these variables underpinned the design of microwave cavities capable of delivering the power density distribution (energy per unit volume over the treatment time) needed to produce the required material effect, consistently at high quality and with maximum treatment efficiency. Buttress et al. also noted the importance of using single mode cavities as the interaction between the applied microwave energy and the material is very difficult to characterise in multi-mode systems owing to the complexity of the electric field pattern. ${ }^{171}$ Integration of the microwave cavity with a materials handling system based on flow requirements (e.g. mixing), and chemical compatibility was also essential. For continuous flow reactors, the design of choking structures to confine the electric field within the microwave system is paramount in order to achieve compliance with safety standards. All of these factors support the successful integration of microwave energy with chemical reactor systems capable of delivering the economic large-scale manufacturing processes at the correct cost and minimal environmental impact.

Current state of the art in industrial manufacture of MOFs has restricted widespread adoption of MOFs for commercial applications, as at scale they deliver poor quality materials, whilst incurring high energy and capital costs, meaning that many applications are not economically viable. Microwave technology can address these challenges through rapid and selective heating, which can increase production rates by orders of magnitude, give controllable product quality and at a reduced energy and potentially capital cost. Furthermore, the cost of MOF production varies considerably depending on the type of MOF, reagents, synthesis temperature, energy and recyclability of reagents; to ensure that the MOFs and reactors being developed are sustainable on a life cycle basis, it is necessary to evaluate their environmental and economic implications from an early stage of development using life cycle assessment (LCA) and techno-economic analysis (TEA). At present, life cycle, environmental and commercial data in the literature are scarce for conventionally heated well-established MOFs and are nonexistent for MOFs synthesised using microwave heating and so further work in this area is much needed. In order for the breakthroughs in research to occur it is our view that there is a requirement to integrate expertise in microwave technology, process engineering design, techno-economic and environmental analyses, and MOF chemistry to deliver a fundamental understanding of the interactions between microwave energy and commercially and scientifically important MOF systems. This knowledge could then be used to deliver the highest quality scientific and engineering breakthroughs to underpin the development of novel scalable and sustainable chemical reactor manufacturing technologies based upon integration of advanced electromagnetic design and process intensification techniques. For successful delivery, this work requires innovation at the boundaries of process assessment and engineering, microwave and materials interaction, process design and materials chemistry. If it can be delivered, we propose that it will commercially unlock the use of MOFs for a number of high impact energy and environmental applications.

\section{Conclusions}

MOFs are an incredibly large and diverse class of materials. The potentially high commercial value of MOFs arises from their high porosity and tuneable pore environment which gives them an extremely high capacity and high selectivity for gas and hydrocarbon applications. Their proposed applications address challenges in energy, environmental sustainability and innovative healthcare. However, challenges in scaling-up MOF production and their high product and environmental cost compared to traditional sorbents has restricted widespread adoption in industry. Therefore, the development of technologies that reduce the cost of manufacture in an efficient and sustainable way is a key enabling step in the transfer of MOF research from the laboratory to industry.

Microwave (MW) technology shows great promise for scale up of MOF synthesis as it offers benefits over other methods including significantly reduced reaction times (from hours to seconds), high space time yields, and improved energy efficiency. However the most noteworthy advantage of microwave heating is the high level of control over MOF properties such as morphology, particle size and phase; achieved by altering the applied power and treatment time. Further control is realised by altering the reaction chemistry through addition of modulators and/or co-reactants and by varying the solvent. Additionally, microwave heating has been shown to facilitate MOF discovery and has the ability to produce new MOFs and MOF-hybrids that are otherwise difficult to prepare or inaccessible by other synthetic approaches. These advantages demonstrate the applicability and value of microwave heating both at laboratory and industrial scales, through acceleration of MOF design and discovery and as a route to large scale production. However, research in the field of microwave synthesis of MOFs is dominated by the use of commercially available multi-mode microwave systems and a lack of understanding of the interactions of reactants and MOFs with the electric field, and crucially, how this informs the design of the scale up processes. MOFs are potential "step-change" materials, but failure to determine this fundamental knowledge thus far explains the general failure in scale-up from the laboratory and to the non-realization of the potential benefits offered.

\section{Conflicts of interest}

There are no conflicts of interest to declare.

\section{List of abbreviations for linkers and MOFs}

DHTP 1,5-Dihydroxyterephthalic acid

TTTPC 1,1',1"1'-Tris(2,4,6-trimethylbenzene-1,3,5-triyl)tris(methylene)-tris(pyridine-4-carboxylic acid)

BTC Trimesic acid (1,3,5-benzenetricarboxylic acid)

BDC Terephthalic acid (1,4-benzenedicarboxylic acid)

HKUST Hong Kong University of Science and Technology 
Ln Lanthanide metal-organic framework

MOF

MIL Materials of Institut Lavoisier

IRMOF Isoreticular MOF

JUC Jilin University, Changchun

UiO University of Oslo

\section{Acknowledgements}

Andrea Laybourn acknowledges the University of Nottingham for the award of a Nottingham Research Fellowship.

\section{References}

1 R. J. Meredith, Engineers' handbook of industrial microwave heating, IET, UK, 1998.

2 S. R. Batten, N. R. Champness, X.-M. Chen, J. GarciaMartinez, S. Kitagawa, L. Öhrström, M. O'Keeffe, S. M. Paik and J. Reedijk, Pure Appl. Chem., 2013, 85, 1715-1724.

3 B. F. Hoskins and R. Robson, J. Am. Chem. Soc., 1989, 111, 5962-5964.

4 B. F. Hoskins and R. Robson, J. Am. Chem. Soc., 1990, 112, 1546-1554.

5 O. M. Yaghi, G. Li and H. Li, Nature, 1995, 378, 703-706.

6 O. M. Yaghi and H. Li, J. Am. Chem. Soc., 1995, 117, 1040110402.

7 O. M. Yaghi and G. Li, Angew. Chem., Int. Ed. Engl., 1995, 34, 207-209.

8 Scopus database search for "Metal-Organic Framework" or "Metal Organic Framework" - Total results 17759-retrieved 01/12/17.

9 J.-R. Li, R. J. Kuppler and H.-C. Zhou, Chem. Soc. Rev., 2009, 38, 1477.

10 Y. Cui, B. Li, H. He, W. Zhou, B. Chen and G. Qian, Acc. Chem. Res., 2016, 49, 483-493.

11 S. Qiu and G. Zhu, Coord. Chem. Rev., 2009, 253, 2891-2911.

12 J. Lee, O. K. Farha, J. Roberts, K. A. Scheidt, S. T. Nguyen and J. T. Hupp, Chem. Soc. Rev., 2009, 38, 1450.

13 L. E. Kreno, K. Leong, O. K. Farha, M. Allendorf, R. P. Van Duyne and J. T. Hupp, Chem. Rev., 2012, 112, 1105-1125.

14 D. Liu, K. Lu, C. Poon and W. Lin, Inorg. Chem., 2014, 53, 1916-1924.

15 P. Kumar, A. Deep and K.-H. Kim, TrAC, Trends Anal. Chem., 2015, 73, 39-53.

16 L. Zhang, H. B. Wu and X. W. (David) Lou, J. Am. Chem. Soc., 2013, 135, 10664-10672.

17 K. J. Lee, J. H. Lee, S. Jeoung and H. R. Moon, Acc. Chem. Res., 2017, 50, 2684-2692.

18 C. L. Jones, A. J. Tansell and T. Easun, J. Mater. Chem. A, 2016, 4, 6714-6723.

19 F.-X. Coudert, Chem. Mater., 2015, 27, 1905-1916.

20 H.-C. Zhou, J. R. Long and O. M. Yaghi, Chem. Rev., 2012, 112, 673-674.

21 N. Stock and S. Biswas, Chem. Rev., 2012, 112, 933-969.
22 M. Rubio-Martinez, C. Avci-Camur, A. W. Thornton, I. Imaz, D. Maspoch and M. R. Hill, Chem. Soc. Rev., 2017, 46, 34533480 .

23 Scopus database search for "Metal-Organic Framework" or "Metal Organic Framework" and "Microwave" - Total results 284-retrieved 20/03/18.

24 Z. Ni and R. I. Masel, J. Am. Chem. Soc., 2006, 128, 1239412395.

25 A. Laybourn, J. Katrib, R. S. Ferrari-John, C. G. Morris, S. Yang, O. Udoudo, T. L. Easun, C. Dodds, N. R. Champness, S. W. Kingman and M. Schröder, J. Mater. Chem. A, 2017, 5, 7333-7338.

26 S. H. Jhung, J.-H. Lee, P. M. Forster, G. Férey, A. K. Cheetham and J.-S. Chang, Chem.-Eur. J., 2006, 12, 7899-7905.

27 Y. K. Hwang, J.-S. Chang, S.-E. Park, D. S. Kim, Y.-U. Kwon, S. H. Jhung, J.-S. Hwang and M. S. Park, Angew. Chem., Int. Ed., 2005, 44, 556-560.

28 N. A. Khan and S. H. Jhung, Cryst. Growth Des., 2010, 10, 1860-1865.

29 R. Xu, W. Pang and Q. Huo, Modern Inorganic Synthetic Chemistry, Elsevier, 2011.

30 J. B. Hasted, Aqueous dielectrics, Chapman and Hall, 1973.

31 A. Metaxis and R. J. Meredith, Industrial Microwave Heating, IET, UK, 1983.

32 G. B. Dudley, R. Richert and A. E. Stiegman, Chem. Sci., 2015, 6, 2144-2152.

33 U. Kaatze and R. Behrends, Tech. Mess., 2009, 69, 5.

34 A. Laybourn, J. Katrib, P. A. Palade, T. L. Easun, N. R. Champness, M. Schröder and S. W. Kingman, Phys. Chem. Chem. Phys., 2016, 18, 5419-5431.

35 W. Liu, L. Ye, X. Liu, L. Yuan, X. Lu and J. Jiang, Inorg. Chem. Commun., 2008, 11, 1250-1252.

36 S. Biswas, M. Grzywa, H. P. Nayek, S. Dehnen, I. Senkovska, S. Kaskel and D. Volkmer, Dalton Trans., 2009, 6487-6495.

37 A. Centrone, T. Harada, S. Speakman and T. A. Hatton, Small, 2010, 6, 1598-1602.

38 J. L. Crane, K. E. Anderson and S. G. Conway, J. Chem. Educ., 2015, 92, 373-377.

39 M. Ma, A. Bétard, I. Weber, N. S. Al-Hokbany, R. A. Fischer and N. Metzler-Nolte, Cryst. Growth Des., 2013, 13, 22862291.

40 G. Y. Yoo, W. R. Lee, H. Jo, J. Park, J. H. Song, K. S. Lim, D. Moon, H. Jung, J. Lim, S. S. Han, Y. Jung and C. S. Hong, Chem.-Eur. J., 2016, 22, 7444-7451.

41 Y.-Y. Liu, S. Couck, M. Vandichel, M. Grzywa, K. Leus, S. Biswas, D. Volkmer, J. Gascon, F. Kapteijn, J. F. M. Denayer, M. Waroquier, V. Van Speybroeck and P. Van Der Voort, Inorg. Chem., 2013, 52, 113-120.

42 L. Hashemi and A. Morsali, CrystEngComm, 2012, 14, 779781.

43 S. Khanjani and A. Morsali, CrystEngComm, 2012, 14, 81378142.

44 L. M. Aguirre-Díaz, M. Iglesias, N. Snejko, E. GutiérrezPuebla and M. Á. Monge, Chem.-Eur. J., 2016, 22, 66546665. 
45 H.-K. Liu, T.-H. Tsao, Y.-T. Zhang and C.-H. Lin, CrystEngComm, 2009, 11, 1462-1468.

46 P.-C. Liang, H.-K. Liu, C.-T. Yeh, C.-H. Lin and V. Zima, Cryst. Growth Des., 2011, 11, 699-708.

47 M. Mazaj, V. Kaucic, A. Golobic and N. Zabukovec Logar, Acta Crystallogr., Sect. C: Cryst. Struct. Commun., 2012, 68, m4-m6.

48 C.-T. Yeh, W.-C. Lin, S.-H. Lo, C.-C. Kao, C.-H. Lin and C.-C. Yang, CrystEngComm, 2012, 14, 1219-1222.

49 C.-Y. Wu, D. S. Raja, C.-C. Yang, C.-T. Yeh, Y.-R. Chen, C.-Y. Li, B.-T. Ko and C.-H. Lin, CrystEngComm, 2014, 16, 9308-9319.

50 C. P. Cabello, C. O. Arean, J. B. Parra, C. O. Ania, P. Rumori and G. T. Palomino, Dalton Trans., 2015, 44, 9955-9963.

51 P. Silva, F. Vieira, A. C. Gomes, D. Ananias, J. A. Fernandes, S. M. Bruno, R. Soares, A. A. Valente, J. Rocha and F. A. A. Paz, J. Am. Chem. Soc., 2011, 133, 15120-15138.

52 Z.-J. Lin, Z. Yang, T.-F. Liu, Y.-B. Huang and R. Cao, Inorg. Chem., 2012, 51, 1813-1820.

53 S. M. F. Vilela, D. Ananias, A. C. Gomes, A. A. Valente, L. D. Carlos, J. A. S. Cavaleiro, J. Rocha, J. P. C. Tomé and F. A. A. Paz, J. Mater. Chem., 2012, 22, 18354-18371.

54 P. Silva, D. Ananias, S. M. Bruno, A. A. Valente, L. D. Carlos, J. Rocha and F. A. Almeida Paz, Eur. J. Inorg. Chem., 2013, 2013, 5576-5591.

55 R. F. Mendes and F. A. Almeida Paz, Inorg. Chim. Acta, 2017, 460, 99-107.

56 P. P. Bag, X.-S. Wang and R. Cao, Dalton Trans., 2015, 44, 11954-11962.

57 H. Li, M. Liang, W. Sun and Y. Wang, Adv. Funct. Mater., 2016, 26, 1098-1103.

58 Y.-S. Bae, K. L. Mulfort, H. Frost, P. Ryan, S. Punnathanam, L. J. Broadbelt, J. T. Hupp and R. Q. Snurr, Langmuir, 2008, 24, 8592-8598.

59 S. Bernt, M. Feyand, A. Modrow, J. Wack, J. Senker and N. Stock, Eur. J. Inorg. Chem., 2011, 2011, 5378-5383.

60 A. C. Kathalikkattil, R. Roshan, J. Tharun, H.-G. Soek, H.-S. Ryu and D.-W. Park, ChemCatChem, 2014, 6, 284-292.

61 A. C. Kathalikkattil, D.-W. Kim, J. Tharun, H.-G. Soek, R. Roshan and D.-W. Park, Green Chem., 2014, 16, 16071616.

62 S. Mukhopadhyay, B. G. Mukhopadhyay, M. F. C. G. da Silva, J. Lasri, M. A. J. Charmier and A. J. L. Pombeiro, Inorg. Chem., 2008, 47, 11334-11341.

63 W. Karuehanon, W. Fanfuenha, A. Rujiwatra and M. Pattarawarapan, Tetrahedron Lett., 2012, 53, 3486-3489.

64 W. Funfuenha, W. Phakhodee and M. Pattarawarapan, Tetrahedron, 2014, 70, 5415-5419.

65 L. Martins, R. Nasani, M. Saha, S. Mobin, S. Mukhopadhyay and A. Pombeiro, Molecules, 2015, 20, 19203-19220.

66 A. D. Martin, T. L. Easun, S. P. Argent, W. Lewis, A. J. Blake and M. Schröder, CrystEngComm, 2017, 19, 603-607.

67 Y. Yoo and H.-K. Jeong, Chem. Commun., 2008, 0, 24412443.

68 Z.-Q. Li, M. Zhang, B. Liu, C.-Y. Guo and M. Zhou, Inorg. Chem. Commun., 2013, 36, 241-244.
69 Y. Abdollahian, J. L. Hauser, I. R. Colinas, C. Agustin, A. S. Ichimura and S. R. J. Oliver, Cryst. Growth Des., 2014, 14, 1506-1509.

70 W.-J. Li, J.-F. Feng, Z.-J. Lin, Y.-L. Yang, Y. Yang, X.-S. Wang, S.-Y. Gao and R. Cao, Chem. Commun., 2016, 52, 3951-3954.

71 H. Bux, F. Liang, Y. Li, J. Cravillon, M. Wiebcke and J. Caro, J. Am. Chem. Soc., 2009, 131, 16000-16001.

72 Y. Yoo, Z. Lai and H.-K. Jeong, Microporous Mesoporous Mater., 2009, 123, 100-106.

73 J. Caro, Curr. Opin. Chem. Eng., 2011, 1, 77-83.

74 H. T. Kwon and H.-K. Jeong, Chem. Commun., 2013, 49, 3854-3856.

75 Y. Zhu, Q. Liu, J. Caro and A. Huang, Sep. Purif. Technol., 2015, 146, 68-74.

76 S. Shahid, K. Nijmeijer, S. Nehache, I. Vankelecom, A. Deratani and D. Quemener, J. Membr. Sci., 2015, 492, 21-31.

77 Y.-S. Li, F.-Y. Liang, H. Bux, A. Feldhoff, W.-S. Yang and J. Caro, Angew. Chem., Int. Ed., 2010, 49, 548-551.

78 A. Centrone, Y. Yang, S. Speakman, L. Bromberg, G. C. Rutledge and T. A. Hatton, J. Am. Chem. Soc., 2010, 132, 15687-15691.

79 S. Xiao, P. Liu, W. Zhu, G. Li, D. Zhang and H. Li, Nano Lett., 2015, 15, 4853-4858.

80 M. Bechelany, M. Drobek, C. Vallicari, A. A. Chaaya, A. Julbe and P. Miele, Nanoscale, 2015, 7, 5794-5802.

81 C. Liu, Y. Wu, C. Morlay, Y. Gu, B. Gebremariam, X. Yuan and F. Li, ACS Appl. Mater. Interfaces, 2016, 8, 2552-2561.

82 N. E. Tari, A. Tadjarodi, J. Tamnanloo and S. Fatemi, J. CO2 Util., 2016, 14, 126-134.

83 R. D. Arrua, A. Peristyy, P. N. Nesterenko, A. Das, D. M. D'Alessandro and E. F. Hilder, Analyst, 2017, 142, 517-524.

84 H. Zhang, J. Zhong, G. Zhou, J. Wu, Z. Yang and X. Shi, J. Nanomater., 2016, 2016, 9648386.

85 H. J. Kitchen, S. R. Vallance, J. L. Kennedy, N. Tapia-Ruiz, L. Carassiti, A. Harrison, A. G. Whittaker, T. D. Drysdale, S. W. Kingman and D. H. Gregory, Chem. Rev., 2014, 114, 1170-1206.

86 J. Klinowski, F. A. Almeida Paz, P. Silva and J. Rocha, Dalton Trans., 2011, 40, 321-330.

87 P. Maniam and N. Stock, Inorg. Chem., 2011, 50, 5085-5097. 88 T. Ahnfeldt, J. Moellmer, V. Guillerm, R. Staudt, C. Serre and N. Stock, Chem.-Eur. J., 2011, 17, 6462-6468.

89 H. Reinsch and N. Stock, Microporous Mesoporous Mater., 2013, 171, 156-165.

90 S. Halis, N. Reimer, A. Klinkebiel, U. Lüning and N. Stock, Microporous Mesoporous Mater., 2015, 216, 13-19.

91 S. H. Jhung, J.-H. Lee and J.-S. Chang, Bull. Korean Chem. Soc., 2005, 26, 880.

92 G. Férey, C. Serre, C. Mellot-Draznieks, F. Millange, S. Surblé, J. Dutour and I. Margiolaki, Angew. Chem., Int. Ed., 2004, 43, 6296-6301.

93 N. A. Khan and S. H. Jhung, Bull. Korean Chem. Soc., 2009, 30, 2921-2926.

94 M. Schlesinger, S. Schulze, M. Hietschold and M. Mehring, Microporous Mesoporous Mater., 2010, 132, 121-127. 
95 Z. Xiang, D. Cao, X. Shao, W. Wang, J. Zhang and W. Wu, Chem. Eng. Sci., 2010, 65, 3140-3146.

96 L. Bromberg, Y. Diao, H. Wu, S. A. Speakman and T. A. Hatton, Chem. Mater., 2012, 24, 1664-1675.

97 E. Haque, N. A. Khan, J. H. Park and S. H. Jhung, Chem.Eur. J., 2010, 16, 1046-1052.

98 J.-S. Choi, W.-J. Son, J. Kim and W.-S. Ahn, Microporous Mesoporous Mater., 2008, 116, 727-731.

99 E. Haque and S. H. Jhung, Chem. Eng. J., 2011, 173, 866-872. 100 Y. Lou, J. Chen, J. Jiang and Q. Bao, Dalton Trans., 2013, 43, 1261-1266.

101 M. Taddei, P. V. Dau, S. M. Cohen, M. Ranocchiari, J. A. van Bokhoven, F. Costantino, S. Sabatini and R. Vivani, Dalton Trans., 2015, 44, 14019-14026.

102 D. Cabooter, A. Fanigliulo, G. Bellazzi, B. Allieri, A. Rottigni and G. Desmet, J. Chromatogr. A, 2010, 1217, 7074-7081.

103 H. Uehara, S. Diring, S. Furukawa, Z. Kalay, M. Tsotsalas, M. Nakahama, K. Hirai, M. Kondo, O. Sakata and S. Kitagawa, J. Am. Chem. Soc., 2011, 133, 11932-11935.

104 M. Tonigold, Y. Lu, B. Bredenkötter, B. Rieger, S. Bahnmüller, J. Hitzbleck, G. Langstein and D. Volkmer, Angew. Chem., Int. Ed., 2009, 48, 7546-7550.

105 A. Dhakshinamoorthy, M. Alvaro, Y. K. Hwang, Y.-K. Seo, A. Corma and H. Garcia, Dalton Trans., 2011, 40, 1071910724.

106 K. Hindelang, A. Kronast, S. I. Vagin and B. Rieger, Chem.Eur. J., 2013, 19, 8244-8252.

107 N. Abhyankar, M. Lee, M. Foley, E. S. Choi, G. Strouse, H. W. Kroto and N. S. Dalal, Phys. Status Solidi RRL, 2016, 10, 600-605.

108 C. Carlucci, H. Xu, B. Federica Scremin, C. Giannini, D. Altamura, E. Carlino, V. Videtta, F. Conciauro, G. Gigli and G. Ciccarella, CrystEngComm, 2014, 16, 1817-1824.

109 M. Yaser Masoomi, A. Morsali and P. C. Junk, RSC Adv., 2014, 4, 47894-47898.

110 E. Haque, N. A. Khan, C. M. Kim and S. H. Jhung, Cryst. Growth Des., 2011, 11, 4413-4421.

111 D. Li, X. Dai, X. Zhang, H. Zhuo, Y. Jiang, Y.-B. Yu, P. Zhang, X. Huang and H. Wang, J. Catal., 2017, 348, 276-281.

112 H. Bunzen, M. Grzywa, M. Hambach, S. Spirkl and D. Volkmer, Cryst. Growth Des., 2016, 16, 3190-3197.

113 B. Liu, Y. He, L. Han, V. Singh, X. Xu, T. Guo, F. Meng, X. Xu, P. York, Z. Liu and J. Zhang, Cryst. Growth Des., 2017, 17, 1654-1660.

114 Y. Sakata, S. Furukawa, C. Kim and S. Kitagawa, Chem. Lett., 2012, 41, 1436-1438.

115 K. M. L. Taylor, W. J. Rieter and W. Lin, J. Am. Chem. Soc., 2008, 130, 14358-14359.

116 W. Guo, W. Sun, L.-P. Lv, S. Kong and Y. Wang, ACS Nano, 2017, 11, 4198-4205.

117 C. Zhang, L. Ai and J. Jiang, J. Mater. Chem. A, 2015, 3, 30743081.

118 A. Chouhan, P. Mayer and A. Pandey, Indian J. Chem., 2015, 54A, 851-857.

119 A. Chouhan, G. Pilet, S. Daniele and A. Pandey, Chin. J. Chem., 2017, 35, 209-216.
120 Calculated from the advertised surface area range of Basolite MOFs on Sigma Aldrich, retrieved 18/09/17.

121 R. Sabouni, H. Kazemian and S. Rohani, Chem. Eng. Technol., 2012, 35, 1085-1092.

122 M. Märcz, R. E. Johnsen, P. D. C. Dietzel and H. Fjellvåg, Microporous Mesoporous Mater., 2012, 157, 62-74.

123 M. R. DeStefano, T. Islamoglu, S. J. Garibay, J. T. Hupp and O. K. Farha, Chem. Mater., 2017, 29, 1357-1361.

124 A. Carné, C. Carbonell, I. Imaz and D. Maspoch, Chem. Soc. Rev., 2011, 40, 291-305.

125 S.-N. Kim, J. Kim, H.-Y. Kim, H.-Y. Cho and W.-S. Ahn, Catal. Today, 2013, 204, 85-93.

126 F.-L. Yuan, Y.-Q. Yuan, M.-Y. Chao, D. J. Young, W.-H. Zhang and J.-P. Lang, Inorg. Chem., 2017, 56, 65226531.

127 S. R. Caskey, A. G. Wong-Foy and A. J. Matzger, Inorg. Chem., 2008, 47, 7751-7756.

128 N. A. Khan, J. S. Lee, J. Jeon, C.-H. Jun and S. H. Jhung, Microporous Mesoporous Mater., 2012, 152, 235-239.

129 N. A. Khan and S. H. Jhung, Coord. Chem. Rev., 2015, 285, 11-23.

130 N. Guillou, C. Livage, M. Drillon and G. Férey, Angew. Chem., Int. Ed., 2003, 42, 5314-5317.

131 J. Górka, P. F. Fulvio, S. Pikus and M. Jaroniec, Chem. Commun., 2010, 46, 6798-6800.

132 N. E. Tari, A. Tadjarodi, J. Tamnanloo and S. Fatemi, Microporous Mesoporous Mater., 2016, 231, 154-162.

133 F. Zhang, X. Zou, W. Feng, X. Zhao, X. Jing, F. Sun, H. Ren and G. Zhu, J. Mater. Chem., 2012, 22, 25019-25026.

134 L. H. Wee, F. Bonino, C. Lamberti, S. Bordiga and J. A. Martens, Green Chem., 2014, 16, 1351-1357.

135 H. Depauw, I. Nevjestic, J. D. Winne, G. Wang, K. Haustraete, K. Leus, A. A. Verberckmoes, C. Detavernier, F. Callens, E. D. Canck, H. M. Vrielinck and P. V. D. Voort, Chem. Commun., 2017, 53, 8478-8481.

136 D. Li, D. Yan, X. Zhang, J. Li, T. Lu and L. Pan, J. Colloid Interface Sci., 2017, 497, 350-358.

137 Z. Wang and S. M. Cohen, Chem. Soc. Rev., 2009, 38, 13151329.

138 K. K. Tanabe and S. M. Cohen, Chem. Soc. Rev., 2011, 40, 498-519.

139 S. M. Cohen, Chem. Rev., 2012, 112, 970-1000.

140 M. S. El-Shall, V. Abdelsayed, A. E. R. S. Khder, H. M. A. Hassan, H. M. El-Kaderi and T. E. Reich, J. Mater. Chem., 2009, 19, 7625-7631.

141 L. Zhang, Z. Su, F. Jiang, Y. Zhou, W. Xu and M. Hong, Tetrahedron, 2013, 69, 9237-9244.

142 F. Wu, L.-G. Qiu, F. Ke and X. Jiang, Inorg. Chem. Commun., 2013, 32, 5-8.

143 W. Dong, C. Feng, L. Zhang, N. Shang, S. Gao, C. Wang and Z. Wang, Catal. Lett., 2016, 146, 117-125.

144 M. Montazerolghaem, S. F. Aghamiri, S. Tangestaninejad and M. R. Talaie, RSC Adv., 2015, 6, 632-640.

145 A. M. Balu, C. S. K. Lin, H. Liu, Y. Li, C. Vargas and R. Luque, Appl. Catal., A, 2013, 455, 261-266.

146 G. Zhu, X. Li, H. Wang and L. Zhang, Catal. Commun., 2017, 88, 5-8. 
147 M. Kim, S. J. Garibay and S. M. Cohen, Inorg. Chem., 2011, 50, 729-731.

148 A. M. Fracaroli, H. Furukawa, M. Suzuki, M. Dodd, S. Okajima, F. Gándara, J. A. Reimer and O. M. Yaghi, J. Am. Chem. Soc., 2014, 136, 8863-8866.

149 J. Bonnefoy, A. Legrand, E. A. Quadrelli, J. Canivet and D. Farrusseng, J. Am. Chem. Soc., 2015, 137, 9409-9416.

150 H.-G. Seok, D.-W. Kim, J.-G. Yang, M.-I. Kim and D.-W. Park, J. Nanosci. Nanotechnol., 2016, 16, 4612-4619.

151 A. M. Fracaroli, P. Siman, D. A. Nagib, M. Suzuki, H. Furukawa, F. D. Toste and O. M. Yaghi, J. Am. Chem. Soc., 2016, 138, 8352-8355.

152 R. W. Flaig, T. M. Osborn Popp, A. M. Fracaroli, E. A. Kapustin, M. J. Kalmutzki, R. M. Altamimi, F. Fathieh, J. A. Reimer and O. M. Yaghi, J. Am. Chem. Soc., 2017, 139, 12125-12128.

153 H.-Y. Huang, C.-L. Lin, C.-Y. Wu, Y.-J. Cheng and C.-H. Lin, Anal. Chim. Acta, 2013, 779, 96-103.

154 C.-L. Lin, S. Lirio, Y.-T. Chen, C.-H. Lin and H.-Y. Huang, Chem.-Eur. J., 2014, 20, 3317-3321.

155 S. Lirio, W.-L. Liu, C.-L. Lin, C.-H. Lin and H.-Y. Huang, J. Chromatogr. A, 2016, 1428, 236-245.

156 W. Guo, W. Sun and Y. Wang, ACS Nano, 2015, 9, 1146211471.

157 J. Tu, X. Zeng, F. Xu, X. Wu, Y. Tian, X. Hou and Z. Long, Chem. Commun., 2017, 53, 3361-3364.

158 R. Dai, W. Sun, L.-P. Lv, M. Wu, H. Liu, G. Wang and Y. Wang, Small, 2017, 13, 1700521.

159 J.-D. Xiao, L.-G. Qiu, X. Jiang, Y.-J. Zhu, S. Ye and X. Jiang, Carbon, 2013, 59, 372-382.

160 C. Zhang, F. Ye, S. Shen, Y. Xiong, L. Su and S. Zhao, RSC Adv., 2015, 5, 8228-8235.
161 X. Yang, H. Xue, Q. Yang, R. Yuan, W. Kang and C.-S. Lee, Chem. Eng. J., 2017, 308, 340-346.

162 C. L. Arthur and J. Pawliszyn, Anal. Chem., 1990, 62, 21452148.

163 Z. Zhang, Z.-Z. Yao, S. Xiang and B. Chen, Energy Environ. Sci., 2014, 7, 2868-2899.

164 A. Samanta, A. Zhao, G. K. H. Shimizu, P. Sarkar and R. Gupta, Ind. Eng. Chem. Res., 2012, 51, 1438-1463.

165 Carbon Capture and Sequestration Market Could Reach \$128 Billion by 2030, https://www.navigantresearch.com/ newsroom/carbon-capture-and-sequestration-marketcould-reach-128-billion-by-2030, accessed May 16, 2017.

166 G. H. Albuquerque, R. C. Fitzmorris, M. Ahmadi, N. Wannenmacher, P. K. Thallapally, B. P. McGrail and G. S. Herman, CrystEngComm, 2015, 17, 5502-5510.

167 S. Cadot, L. Veyre, D. Luneau, D. Farrusseng and E. A. Quadrelli, J. Mater. Chem. A, 2014, 2, 17757-17763.

168 M. Taddei, D. A. Steitz, J. A. van Bokhoven and M. Ranocchiari, Chem.-Eur. J., 2016, 22, 3245-3249.

169 C. McKinstry, E. J. Cussen, A. J. Fletcher, S. V. Patwardhan and J. Sefcik, Chem. Eng. J., 2017, 326, 570-577.

170 M. Taddei, N. Casati, D. A. Steitz, K. C. Dümbgen, J. van Bokhoven and M. Ranocchiari, CrystEngComm, 2017, 19, 3206-3214.

171 A. J. Buttress, J. Katrib, D. A. Jones, A. R. Batchelor, D. A. Craig, T. A. Royal, C. Dodds and S. W. Kingman, Miner. Eng., 2017, 109, 169-183.

172 A. R. Batchelor, A. J. Buttress, D. A. Jones, J. Katrib, D. Way, T. Chenje, D. Stoll, C. Dodds and S. W. Kingman, Miner. Eng., 2017, 111, 5-24. 